CARRA Working Paper Series

Working Paper \#2014-09

\title{
America's Churning Races: \\ Race and Ethnic Response Changes between Census 2000 and the 2010 Census
}

\author{
Carolyn A. Liebler \\ University of Minnesota \\ Sonya Rastogi \\ U. S. Census Bureau \\ Leticia E. Fernandez \\ U. S. Census Bureau \\ James M. Noon \\ U. S. Census Bureau \\ Sharon R. Ennis \\ U. S. Census Bureau
}
Center for Administrative Records Research and Applications
U.S. Census Bureau
Washington, D.C. 20233




\title{
America's Churning Races: Race and Ethnic Response Changes between Census 2000 and the 2010 Census
}

August 4, 2014

Carolyn A. Liebler, University of Minnesota

Sonya Rastogi, U. S. Census Bureau

Leticia E. Fernandez, U. S. Census Bureau

James M. Noon, U. S. Census Bureau

Sharon R. Ennis, U. S. Census Bureau

\begin{abstract}
Race and ethnicity responses can change over time and across contexts - a component of population change not usually taken into account. To what extent do race and/or Hispanic origin responses change? Is change more common to/from some race/ethnic groups than others? Does the propensity to change responses vary by characteristics of the individual? To what extent do these changes affect researchers? We use internal Census Bureau data from the 2000 and 2010 censuses in which individuals' responses have been linked across years. Approximately 9.8 million people (about 6 percent) in our large, non-representative linked data have a different race and/or Hispanic origin response in 2010 than they did in 2000. Several groups experienced considerable fluidity in racial identification: American Indians and Alaska Natives, Native Hawaiians and Other Pacific Islanders, and multiple-race response groups, as well as Hispanics when reporting a race. In contrast, race and ethnic responses for single-race non-Hispanic whites, blacks, and Asians were relatively consistent over the decade, as were ethnicity responses by Hispanics. People who change their race and/or Hispanic origin response(s) are doing so in a wide variety of ways, as anticipated by previous research. For example, people's responses change from multiple races to a single race, from a single race to multiple races, from one single race to another, and some people add or drop a Hispanic response. The inflow of people to each race/Hispanic group is in many cases similar in size to the outflow from the same group, such that cross-sectional data would show a small net change. We find response changes across ages, sexes, regions, and response modes, with variation across groups. Researchers should consider the implications of changing race and Hispanic origin responses when conducting analyses and interpreting results.
\end{abstract}

Key words: Race, Hispanic origin, Response change, Census 2000, 2010 Census 


\section{INTRODUCTION}

Race and ethnicity ${ }^{1}$ are fundamental and consequential in shaping people’s lives and experiences. They define key elements of the American experience, influencing how people see themselves, how they are seen and treated, and to which communities they feel connected. Race and ethnicity are also correlated with most achieved characteristics, including health, income, education, employment, marital status, and involvement in the military or prison system (c.f. Farley and Haaga 2005; Mehta et al. 2013). Because they are ubiquitous to life in America, many people assume that a person’s race and ethnicity are stable and essential characteristics.

However, race and ethnic groups are not inherent divisions of society. Social scientists have shown that the definition of each group and the concept of the "typical” member are socially constructed (in ways that vary over time and place) by political regimes, through intergroup relations, and via personal interaction (c.f. Barth 1969; Haney López 1996). Relatedly, people sometimes change their sense of which race(s) best describe them, or whether they are Hispanic.

Social scientists, policy makers, and the public often treat race and ethnicity as in-born and life-long (see Wimmer 2013 for a discussion). Thus, analysts commonly examine change in race/ethnic inequalities by comparing race/ethnic data from a nationally representative study at Time 1 to another at Time 2. Any change over time is assumed to be due to birth, death,

\footnotetext{
${ }^{1}$ In this research, we apply the terms "race” and "Hispanic origin” in congruence with the federal statistical definitions and guidelines used to collect the data. Federal agencies such as the U.S. Census Bureau must adhere to the Office of Management and Budget's (OMB) race and Hispanic origin standards and definitions, last revised in 1997 with the following race categories: white, black or African American ("black” here), American Indian or Alaska Native (“American Indian” here), Asian, and Native Hawaiian or Other Pacific Islander ("Pacific Islander” here). The Census Bureau was granted special permission to add an "other" race category for those who do not identify with the 5 standard race categories ("Some Other Race” or "SOR" here). In 1997, OMB also defined two ethnicity categories: Hispanic and non-Hispanic; in this paper, we use the terms Hispanic origin and ethnicity interchangeably (Office of Management and Budget 1997).
} 
migration, or random error. The possibility of individual respondents changing their race/ethnic categories is rarely considered or is assumed to be part of some random error process.

Some scholars (e.g., Guo et al. 2014; Harris and Sim 2002; Liebler and Ortyl 2014; Saperstein and Penner 2012) have investigated individuals’ changing race/ethnicity answers using the little data available. Scholars do so to learn about the social construction of race, and because dynamic group membership has real consequences for measured trends in inequalities. If a person changes her response from A to B, the measured attributes of both groups will change. For example, if she has a high education, group B's mean education will rise and group A's will fall. Statistics changed over time, yet no individual gained (or lost) education.

Many studies of race and Hispanic origin response changes use relatively small datasets or have done qualitative work and focus on just one or two populations. These scholars have raised important questions and given helpful glimpses into the phenomena, but empirical studies to date have been constrained by small sample sizes; many questions remain unanswered. We build on prior research using much larger and more diverse data than previously available. This allows us to include all federally-defined race and Hispanic origin groups and to provide the first measurements of the extent of race and ethnic response changes across the diversity of America. We ask fundamental questions about changes in race and Hispanic origin reports. ${ }^{2}$ To what extent do race and/or Hispanic origin responses ${ }^{3}$ change? Is change more common to/from

\footnotetext{
${ }^{2}$ In this research, we sometimes discuss response change in general. Note, however, that not all response changes have the same meaning. For instance, people can be expressing a variety of identities by marking multiple races; there are probably meaningful differences between those people who combine two socially- and federally-identified races (e.g., white and black) and those people reporting one of those races (e.g., black) in combination with SOR. Also, adding or dropping a second race (e.g., changing from white to white-black) could be a different phenomenon than switching from one single race to another (e.g., changing from white to black). For ease of presentation, we show response changes for all race and Hispanic origin groups in a parallel fashion, but we urge our readers to keep these nuances in mind when considering our results.
} 
some race/ethnic groups than others? Does the propensity to change responses vary by characteristics of the individual? And to what extent do race and Hispanic origin response changes affect researchers? We use a variety of strategies to address these questions. (1) We use descriptive statistics and data visualization to show the extent of response stability and change. (2) We examine the top 20 race/Hispanic changes in terms of sex, age, region, and response mode. (3) We detail response changes through case studies of three subsets of race/Hispanic groups. (4) We provide age, sex, and race/Hispanic group-specific information about the rates of race and/or Hispanic response change in our data. (5) We estimate the total level of race/Hispanic response change among all people who took part in Census 2000. (6) We examine the effects of response change on aggregated categories of race and Hispanic origin.

The data we use are remarkably well suited for this work; they are internal Census Bureau data from two U.S. censuses that have been linked to each other at the individual level to make a very large longitudinal data set containing about 162 million people, after case selection. These uniquely rich data enable our distinctively comprehensive assessment of recent individuallevel response changes among all federally-defined race and ethnic groups. With empirical data on 2000 and 2010 census responses for more than half of the U.S. population, we surpass previous research limited by relatively small samples sizes, a focus on few race or Hispanic populations, or limited to studying a single type of response change.

Our results have the potential to shift understandings of how people experience and navigate race in our society. For example, cross-group differences in levels and types of response

\footnotetext{
${ }^{3}$ Because of our case selection (described below), we are confident that these are mostly self-reports or reports by someone else in the household. However, we cannot know who in the household filled out the form (see Sweet 1994 for related estimates). Also, even though instructed otherwise, some enumerators may have influenced race and Hispanic origin reporting in some circumstances. To simplify the prose, we write as though these are self-reports.
} 
change may reflect important differences in the social construction of race/ethnicity across groups. The results also have consequential implications for social scientists who take into account race and/or ethnicity yet rely on the implicit assumption that these are life-long, immutable characteristics (see Saperstein, Penner, and Light 2013). Our work highlights the extent to which this assumption is untenable, as well as areas where the assumption holds.

\section{PRIOR RESEARCH}

\section{To What Extent Do Race and/or Hispanic Origin Responses Change? Which Race/Hispanic Groups Are Most Affected by Response Change?}

Census Bureau researchers, demographers, and sociologists have documented that race and Hispanic origin responses can and do change (c.f., Harris and Sim 2002; Liebler and Ortyl 2014; Nagel 1996; Passel 1976; Root 1996; Sturm 2011; U.S. Census Bureau 1993). The Census Bureau has decades of experience researching and documenting race and ethnic response change. For example, the Census Bureau conducts reinterviews with a large sample of households immediately after the decennial census in order to evaluate data quality. Recent census reinterview studies have found that race responses can change even over a short period. In the 1990 Census Reinterview Study, 4 percent of individuals had a different race response in the reinterview than in the census (U.S. Census Bureau 1993). This number was 8 percent in the 2000 reinterview study (Singer and Ennis 2003) and 6 percent in the 2010 study (Dusch and Meier 2012). Research on adolescents and young adults shows a relatively high level of race response change among young people. For example, Harris and Sim (2002) found that 12 percent of adolescents reported a different race at home versus at school in the 1994-95 wave of the National Longitudinal Study of Adolescent Health (Add Health). 
Race response change varies substantially by race group, with whites, blacks, and Asians standing out as especially consistent. Comparing Census 2000 responses to responses in the February-May waves of the 2000 Current Population Survey (CPS), del Pinal and Schmidley (2005) found that non-Hispanic single-race whites, blacks, and Asians had more consistent race responses than did American Indians and Pacific Islanders. Almost all (97 to 98 percent) of white, black, and Asian Census 2000 respondents gave the same response in the Census Quality Survey (CQS) - a survey fielded later in 2000 and explicitly designed to reach the same individual who responded in Census 2000 (Bentley et al. 2003). Between Waves I and III of Add Health, single-race white, black, and Asian adolescents exhibited the most consistency in responses across waves (Doyle and Kao 2007). Some people in these groups have mixed heritage, for example children of interracial marriages for whom only one race is reported (c.f., Liebler and DeRousse-Wu 2012). If even a small proportion of a large group changes their response, the number of people doing so could be large.

Response changes are much more common in other groups. Only 19 percent of those who reported white-American Indian in Wave I of Add Health did so in Wave III (Doyle and Kao 2007). Of American Indian, Pacific Islander, and Some Other Race respondents in Census 2000, between 55 and 78 percent gave the same response in the CQS (Bentley et al. 2003). Only about 40 percent of those who reported multiple races in Census 2000 also reported multiple races in the CQS (Bentley et al. 2003).

People are relatively consistent in their Hispanic responses in the census and reinterviews - in 1990, only 2 percent changed their answer to whether or not they have Hispanic origins (U.S. Census Bureau 1993), 3 percent changed responses in 2000 (Singer and Ennis 2003), and 1 percent changed responses in 2010 (Dusch and Meier 2012). Comparing Census 2000 to CPS 
revealed that 3 percent of respondents reported being Hispanic in one of these data sets but not in the other (del Pinal and Schmidley 2005), though differences in response mode and question format play a part in this comparison.

Past research shows substantial variation in race responses given by Hispanics, with less race response change by non-Hispanics. For example, del Pinal and Schmidley (2005, Table 13) found that 87 percent of those who reported Hispanic white in Census 2000 gave the same race/Hispanic response in the CPS. The percentage of people providing the same race/Hispanic response in Census 2000 and the 2000 CPS was considerably lower for those who reported (in Census 2000) Hispanic black (55 percent) and Hispanic American Indian (22 percent). Among non-Hispanics in Census 2000, they found that 99 percent of whites, 95 percent of blacks, and 73 percent of American Indians reported the same way in the CPS. They also found that 88 percent of non-Hispanic Asians in Census 2000 and 72 percent of non-Hispanic Pacific Islanders reported non-Hispanic “Asian or Pacific Islander” in the CPS.

Prior researchers have used qualitative methods, relatively small longitudinal survey data sets, and/or logic, inference, and cross-sectional data to discern why some race/ethnic groups have more fluidity in race and/or Hispanic origin responses. The relevant research falls under several themes: (a) border identities of multiracial people, (b) Hispanic respondents' views of the race question, (c) adding or dropping identification as Hispanic, (d) changing responses among American Indians and Pacific Islanders, and (e) changing responses from one single race to another. There is little prior research on why race responses are relatively stable among nonHispanic single-race whites, blacks, and Asians.

Border identities of multiracial people: Multiracial people, especially those whose parents are of different single-race groups, have been documented as having a rather dynamic 
and border-straddling racial self-concept that is not easily brought into standard race categories (c.f., Rockquemore 1998; Root 1996). In addition, sometimes their self-presentation is at odds with their family heritage and/or personal identities (Khanna and Johnson 2010). In as much as their feelings and experiences vary across time and context, their answers to race questions may vary between marking both/all of their affiliated groups and marking only one.

Different multiracial subgroups may be more likely to change their race compared to others. For instance, the social and legal history of the United States has defined the "black" and “white” categories relatively strictly (Davis 2001; Haney López 1996) and may provide less flexibility for part-blacks and part-whites compared to other multiracial subgroups (Doyle and Kao 2007; Gullickson and Morning 2011; Guo et al. 2014; Harris and Sim 2002). People with American Indian and white heritage, for example, tend to show more flexibility in how they report their race(s) (c.f., Doyle and Kao 2007; Sturm 2011). There is evidence that multiracial part-Asians are particularly likely to report their mixed heritage on a census form (c.f., Gullickson and Morning 2011; Liebler and DeRousse-Wu 2012), perhaps because they do not feel comfortable reporting single-race Asian (see King-O’Riain 2004; Spickard 2001).

Hispanic respondents' views of the race question: There are a number of factors that might heighten variation in race responses among Hispanics relative to non-Hispanics. First, though the American public often thinks of Hispanic as a race category, the federal government defines Hispanic origin as an ethnicity and collects data on race and ethnicity in two separate questions. The census race question has no "Hispanic" answer category. People who view their race as Hispanic may be relatively uncommitted to their response to this question that does not fit their self-conception (c.f., Compton et al. 2012; Rodríguez 2000). Second, people may not see their identity captured in U.S. racial categories if they identify with Latin American terms such 
as mulatto or mestizo (Golash-Boza and Darity 2008). Third, immigrants from all groups, including some foreign-born Hispanics, might also change their identities and race/Hispanic responses through processes such as assimilation or segmented assimilation (c.f., Waters 1999). Fourth, over the years, the Census Bureau has changed questionnaire design to encourage Hispanics to report at least one of the five federally-defined race categories, rather than writing in a response that does not fit one of these groups (e.g., "Mexican”). Questionnaire design changes may have influenced some Hispanics to change their racial response to the census (see Stokes et al. 2011). At the same time, some Hispanics may be committed to their race response. They may, for example, view themselves as white (c.f., Golash-Boza and Darity 2008; Logan 2003; Tafoya 2004), and consistently report this as their race.

Adding or dropping identification as Hispanic: In addition to race changes among Hispanics, there are also studies documenting Hispanic origin identification changes. For example, there is evidence that some multigenerational Mexican Americans do not report this heritage in the Hispanic origin question, especially if one parent is non-Hispanic or if the family is affluent (Alba and Islam 2009; Duncan and Trejo 2011). Other studies have found more direct evidence of individuals of Hispanic descent changing whether or not they self-report Hispanic origin (Eschbach and Gomez 1998; Perez 2008). These studies primarily focus on those who move from Hispanic identification to non-Hispanic identification. Changes in the opposite direction - from non-Hispanic to Hispanic - are covered in our research as well. On the 2010 Census, the word "origin" was added to the Hispanic question. This questionnaire change might have encouraged people with thin ties (Cornell and Hartmann 2007) to their Hispanic heritage to report Hispanic origin on the census form in 2010 (Lavrankas et al. 2005; Stokes et al. 2011). 
Changing responses among American Indians and Pacific Islanders: Tribal, legal, and social definitions of who is considered American Indian have been governed by rules that exclude some people of American Indian heritage (c.f., Robertson 2013; Snipp 2003), for example many federally recognized tribes require a minimum blood quantum for enrollment (Thornton 1997). Over the past half century, this "hyperdescent” rule has perhaps lost influence as more people have marked American Indian on the census race question and identified as American Indian in daily life (Eschbach 1993, 1995; Eschbach et al. 1998; Fitzgerald 2007; Harris 1994; Liebler and Ortyl 2014; Nagel 1996; Passel 1976, 1997; Passel and Berman 1986; Sturm 2011).

Both the American Indian population and the Pacific Islander population have a high proportion of people who report multiple races—about 44 percent of American Indians and 56 percent of Pacific Islanders also reported at least one other race in the 2010 Census (Humes et al. 2011). As described above, identities (and responses) have been found to be particularly fluid among self-identified multiracial people. Research on racial identity and race responses by American Indians and Pacific Islanders points to cultural connections and relationships to homeland places as important factors that influence how (and whether) mixed heritage is reported (c.f., Kana’iaupuni and Liebler 2005; Liebler and Kana'iaupuni 2003/4; Liebler 2010; Spikard and Fong 1995).

Changing responses from one single race to another: Prior to 1997, the federal statistical system did not allow the option for people to report their multiracial heritage. Some studies using data collected by the federal government prior to 1997 have observed people changing a single-race report to another single-race report (c.f., Eschbach, Supple, and Snipp 1998; Harris 1994; Passel 1976). There is also evidence of response changes from one single race to another 
among adolescents of mixed heritage, although the prevalence is relatively low (Harris and Sim 2002). Some single-race-to-single-race response changes are a reflection of identity awakenings (c.f., Fitzgerald 2007; Sturm 2011). Other such response changes could arise if a mixed-heritage person changes contexts, reference group orientation, socioeconomic status, or has a "chameleon change” experience (c.f., Kana’iaupuni and Liebler 2005; Liebler 2010; Miville et al. 2005; Stokes-Brown 2012). Perhaps because of data limitations and because it is so far afield from the understanding of race as a lifetime characteristic, single-race-to-single-race response changes have not been directly studied in most recent research. Our data are well suited to document the extent and patterns of these types of response change.

\section{Likely Characteristics of People Who Change Their Race/Hispanic Response}

There are many reasons why a person's race and/or Hispanic origin response might change. For example, people may have different race/Hispanic identities highlighted in different situations and this could be reflected in their answers (Harris and Sim 2002; Rodriguez 2000; Root 1996). Household members might differ in their interpretation of another household member’s race/Hispanic origin, causing a measured change when respondents change. Involvement in new social networks and interactions - as when going to college, moving to a new area, or changing socioeconomic status - can also impact identity and thus reporting (c.f., Eschbach 1993: Kana’iaupuni and Liebler 2005; Root 1998). New immigrants sometimes undergo a transformation of their self-identified race as they come to understand, and perhaps accept, how the American public sees them (c.f., Landale and Oropesa 2002; Waters 1999). Even small changes in questionnaire design or data collection procedures can affect how people respond to a questionnaire (c.f., Lavrankas et al. 2005; Snipp 2003; Stokes et al. 2011). Changes 
in post-processing procedures such as coding and editing can also impact whether data show a person’s response as having changed.

Our data are not well suited for parsing the reasons for race and Hispanic response change and stability. Rather than attempt this, our goals are to document the extent of the response change and give information about patterns of response change. We do provide summary information about a few characteristics that can be discerned from the limited information available in our data, however, in order to help future research efforts.

Besides race and Hispanic origin information, the data tell us about the person's sex, age, location, and enumeration mode. ${ }^{4}$ There is some evidence that women are socialized to have more complex and nuanced identities than men (see Root 1998); perhaps more women than men in our data will change their race/Hispanic responses. Compared to adults, children and adolescents may be more likely to change their race/Hispanic responses for two reasons: (a) childhood and adolescence are times of personal identity development (c.f. Erickson 1980), and (b) young people's information was probably reported by their parents in 2000 but may be selfreported in 2010. The West region has higher levels of interracial marriage and of multiple-race reporting than elsewhere in the country (c.f., Jones and Bullock 2012; Wright et al. 2003), so we may see more response change in the West than in other regions. ${ }^{5}$ Finally, the presence of an enumerator (as opposed to a form that was submitted to the Census Bureau by mail) ${ }^{6}$ may cause

\footnotetext{
${ }^{4}$ In future research, we intend to explore these characteristics in more detail and incorporate measures of household structure.

${ }^{5}$ The census definition of the West region includes: Alaska, Arizona, California, Colorado, Hawaii, Idaho, Montana, Nevada, New Mexico, Oregon, Utah, Washington, and Wyoming.

${ }^{6}$ Enumerators are involved when the household does not return the mailed census form, the address resides in area that consists of mostly seasonal homes and in some extremely rural areas such as western American Indian reservations, Alaska Native areas, and rural Maine (Fallica et al. 2012; Walker et al. 2012).
} 
change in race or Hispanic origin responses. An enumerator might impact census race or Hispanic origin responses through several pathways. For example, the respondent may experience a social psychological process when talking with a stranger (e.g., reflected appraisal; c.f., Khanna 2004), especially someone representing the federal government. Or an enumerator's opinion of the respondent's race or Hispanic origin could filter into the responses (despite instructions to the contrary). Race reports by any outsider, including enumerators, are less consistent than self-reports (c.f., Saperstein and Penner 2012) and could increase the chances of a change in reported race and/or Hispanic origin.

\section{To What Extent Do These Changes Affect Researchers?}

Researchers often rely on the assumption that a racial or ethnic group includes the same individuals at each time point, except for differences due to births, migration, and deaths. For example, someone wishing to know whether American Indians are becoming more socioeconomically similar to whites over time might use cross-sectional data on American Indians in one year and compare it to cross-sectional data on American Indians in another year. The issue affects point-in-time correlations as well. For example, someone wanting to know why people live in residentially segregated areas would start by comparing group-specific patterns (then, for example, conduct analyses intended to account for other factors besides discrimination). Often data limitations reinforce the decision not to take into account race/ethnic response change when generating statistics, whether point-in-time correlations or cross-time comparisons.

In both of these examples, race/ethnic response change might be one of the factors impacting data and statistics. A change over time in the average income of American Indians, for example, can be a reflection of change in individuals' incomes as well as differences between the 
income of those who stopped reporting American Indian and those who began reporting American Indian. A level of residential segregation between Asians and blacks can reflect: (a) experiences of people who consistently identify as Asian and as black, (b) experiences that cause some people to be more likely to identify with each group, and (c) experiences that cause some people to be less likely to identify with each group. Statistics should be understood with this complexity in mind. This caution extends not only to people conducting analyses and writing research reports, but also to the readers of those reports as they interpret the results.

\section{DATA}

The U.S. Census Bureau has linked individuals' census records as part of an effort to understand response variability and reduce data collection costs. We use internal Census Bureau data from the 2000 and 2010 censuses in which individuals' responses have been linked across years by the Census Bureau's Center for Administrative Records Research and Applications (CARRA). CARRA uses probability record linkage techniques and personal information such as name and date of birth to assign an anonymized "Protected Identification Key" or PIK to each person, as possible (see Wagner and Layne 2014). The data do not include people who do not have a Social Security Number and those whose personal information was too ambiguous or incomplete to assign a PIK. ${ }^{7}$ Once the PIK was assigned in each separate data set, it was used to link a person's record in one census or survey (in this case, Census 2000) to his or her own record in another census or survey (in this case, the 2010 Census). The linked data can be used only for Census Bureau statistical purposes and by approved researchers.

\footnotetext{
${ }^{7}$ The system that is used to uniquely identify individuals - the Person Identification Validation System or PVS - is slightly better able to identify non-Hispanic whites than other groups (see Bond et al. 2013).
} 
Because the data are linked across a decade, our study naturally excludes people who answered Census 2000 but who died or left the country by 2010. Similarly, new immigrants who arrived after 2000, and children born after Census 2000, are by definition not included in the linked data. The data also naturally exclude people who were present but not enumerated in Census 2000 and/or the 2010 Census (Mule 2012; U.S. Census Bureau 2003). We begin with the population of people who were present, enumerated, and assigned a unique PIK in the full-count decennial censuses of 2000 and 2010 -199,917,723 individuals. ${ }^{8}$ This is 81 percent of the people with unique PIKs in 2000.

For the analyses presented here, we apply case selection restrictions to the data to reduce the chances that response changes are due to enumeration issues ${ }^{9}$ or false matches. ${ }^{10}$ In the results presented below, we exclude cases in which: (a) the person lived in group quarters (6,845,302 cases excluded); (b) information was collected from a neighbor or other respondent outside of the household $(4,868,556)$; (c) the race or Hispanic origin was imputed or edited by the Census Bureau (21,144,912); (d) the person’s age difference between the two censuses was less than 8 years or more than 12 years $(5,410,733)$ or all age information in a year was imputed $(3,994,504)$; (e) the person's sex did not match between the two censuses $(1,232,272)$ or sex information in a year was imputed $(3,885,179)$; (f) the person was listed as SOR and another race

\footnotetext{
${ }^{8}$ People in Census 2000 who could not be linked to 2010 had an older age distribution, were more likely to be reported as non-Hispanic black or Hispanic, and were less likely to be non-Hispanic white.

${ }^{9}$ Write-in responses were categorized into federally-defined race groups using slightly different protocols in 2000 and 2010. We correct for this by applying the 2010 coding scheme to write-in responses given in 2000 .

${ }^{10}$ Some PIKs are probably not assigned to the correct person. Based on an assessment of false matches in linked census data (Layne et al. 2014), we anticipate that 0.2 percent to 1.2 percent of the cases in our data are false matches. As Hemenway (1997) pointed out, false matches disproportionately affect rates for rare events or, in this case, numerically small groups. See Appendix Table A for related calculations.
} 
in $2000(1,903,447 \text { cases })^{11}$; or (g) the person filled out an Alternative Questionnaire Experiment census form in $2010(347,301)$. Because we excluded some cases for multiple reasons, the sum of these numbers is greater than the number of records removed from the sample. Our analysis data contain the full set of people who fit criteria (a) through (g) - 161,700,185 people, of whom 9,782,918 (or 6.1 percent) had a different race and/or Hispanic response in 2010 than they did in $2000 .^{12}$

Because we are using total U.S. population data from both decennial censuses (not using sample data), there are no weights. In other words, the matched data are not nationally representative and should not be interpreted as such. To clarify the relationship between our data and the total U.S. population in 2000 and 2010, we show in Table 1 the distribution of race and Hispanic responses in the 162 million cases in our analysis data and compare them to parallel numbers for the full 2000 and 2010 population data (Grieco and Cassidy 2001; Humes et al. 2011). As the last two columns of Table 1 show, not all groups of people were equally likely to be included in our study. Almost two-thirds of non-Hispanic whites (64 percent of the 2000 population) are in our study data, but only 20 percent of the 2010 population of Some Other Race Hispanics are included. To understand race and Hispanic response change for all U.S. persons, we apply the response change rates in our data (shown in Table 7 and Appendix Table C) to the full 2000 population. This gives us an estimate of the expected amount of race and/or Hispanic

\footnotetext{
${ }^{11}$ This group was subject to coding errors in 2000 as described in U.S. Census Bureau 2007, Data Note 5: "In Census 2000, during the conversion process of making the race write-in entries on the enumerator-filled questionnaire consistent with those in the mailout/mailback questionnaire, a step was inadvertently omitted. This resulted in an overstatement by about 1 million people reporting more than one race (or about 15 percent of the Two or More Races population). This overstatement almost entirely affects race combinations involving Some Other Race with the five race groups identified by the Office of Management and Budget (White, Black or African American, American Indian or Alaska Native, Asian, and Native Hawaiian or Other Pacific Islander).”

${ }^{12}$ Coding procedures for write-in lines changed from 2000 to 2010 for those who wrote more than two race responses on one write-in line. This may have a small impact on our results.
} 
Table 1. Census 2000 and 2010 Census official United States population totals in comparison to linked data used in this study

\begin{tabular}{|c|c|c|c|c|c|c|}
\hline \multirow[t]{2}{*}{2000} & \multicolumn{2}{|c|}{ Official U.S. Total } & \multicolumn{2}{|c|}{ Linked data in this study } & \multicolumn{2}{|c|}{$\%$ of US total in study data } \\
\hline & Non-Hispanic & Hispanic & Non-Hispanic & Hispanic & Non-Hisp. & Hispanic \\
\hline white & $\overline{194,552,774}$ & $\overline{16,907,852}$ & $124,765,953$ & $6,901,238$ & $64 \%$ & $41 \%$ \\
\hline black & $33,947,837$ & 710,353 & $15,454,761$ & 238,070 & $46 \%$ & $34 \%$ \\
\hline AIAN & $2,068,883$ & 407,073 & $1,045,627$ & 163,775 & $51 \%$ & $40 \%$ \\
\hline Asian & $10,123,169$ & 119,829 & $5,599,943$ & 50,981 & $55 \%$ & $43 \%$ \\
\hline NHPI & 353,509 & 45,326 & 152,640 & 12,245 & $43 \%$ & $27 \%$ \\
\hline SOR & 467,770 & $14,891,303$ & 207,906 & $5,011,234$ & $44 \%$ & $34 \%$ \\
\hline Two or More Races* & $4,602,146$ & $2,224,082$ & $1,917,960$ & 177,852 & $42 \%$ & $8 \%$ \\
\hline Total & \multicolumn{2}{|c|}{$281,421,906$} & \multicolumn{2}{|c|}{$161,700,185$} & \multicolumn{2}{|c|}{$57.5 \%$} \\
\hline 2010 & \multicolumn{2}{|c|}{ Official U.S. total } & \multicolumn{2}{|c|}{ Linked data in this study } & \multicolumn{2}{|c|}{$\%$ of US total in study data } \\
\hline & Non-Hispanic & Hispanic & Non-Hispanic & $\overline{\text { Hispanic }}$ & Non-Hisp. & Hispanic \\
\hline white & $\overline{196,817,552}$ & $26,735,713$ & $124,156,954$ & $8,141,069$ & $63 \%$ & $30 \%$ \\
\hline black & $37,685,848$ & $1,243,471$ & $15,284,628$ & 279,972 & $41 \%$ & $23 \%$ \\
\hline AIAN & $2,247,098$ & 685,150 & $1,042,724$ & 168,481 & $46 \%$ & $25 \%$ \\
\hline Asian & $14,465,124$ & 209,128 & $5,575,803$ & 52,024 & $39 \%$ & $25 \%$ \\
\hline NHPI & 481,576 & 58,437 & 154,925 & 11,184 & $32 \%$ & $19 \%$ \\
\hline SOR & 604,265 & $18,503,103$ & 149,739 & $3,614,224$ & $25 \%$ & $20 \%$ \\
\hline Two or More Races & $5,966,481$ & $3,042,592$ & $2,376,310$ & 692,148 & $40 \%$ & $23 \%$ \\
\hline Total & \multicolumn{2}{|c|}{$308,745,538$} & \multicolumn{2}{|c|}{$161,700,185$} & \multicolumn{2}{|c|}{$52.4 \%$} \\
\hline
\end{tabular}

Note: AIAN = American Indian/Alaska Native; NHPI = Native Hawaiian and other Pacific Islander; SOR = Some Other Race.

* Due to a processing error potentially affecting our results, we do not study people in 2000 who were coded as more than one race including Some Other Race. Most of the excluded people were likely Hispanic.

Sources: Official total for Census 2000: Table 10 of C2KBR01-1 by Greico and Cassidy; official total for Census 2010: Table 2 of 
response change if all people in Census 2000 had survived and been enumerated in 2010. We report these results below.

Some questionnaire design changes occurred between Census 2000 and the 2010 Census $^{13}$ and so the race and Hispanic origin responses in 2000 are not strictly comparable to responses in 2010. These design changes probably impacted some groups more than others. For example, the 2010 instruction "For this census, Hispanic origins are not races," was intended to encourage reporting in one of the five federally-defined race groups as opposed to marking the Some Other Race checkbox response category or writing in a response that could not be classified within the OMB race groups. Evidence suggests that the instruction had the intended effect (Stokes et al. 2011).

There are several ways in which these data are uniquely well suited to study cross-time changes in individuals' race and Hispanic responses. First, we have responses from individuals at two points in time and can directly observe response change, as opposed to using crosssectional data and inferring response change. Second, our data cover a considerable portion of the U.S. population and are sufficiently dense to allow disaggregation into the many federallydefined race/Hispanic origin categories in each census. Third, these are the U.S. decennial census

\footnotetext{
${ }^{13}$ An instruction was added to the 2010 Census indicating "Please answer BOTH Question 5 about Hispanic origin and Question 6 about race. For this census, Hispanic origins are not races.” There were two changes to the race question from 2000 to 2010, as Humes et al. (2011:2) explain: "First, the wording of the race question was changed from 'What is this person's race? Mark one or more races to indicate what this person considers himself/herself to be' in 2000 to 'What is this person's race? Mark one or more boxes' for 2010. Second, in 2010, examples were added to the 'Other Asian' response category (Hmong, Laotian, Thai, Pakistani, Cambodian, and so on) and the 'Other Pacific Islander' response category (Fijian, Tongan, and so on). In 2000, no examples were given in the race question." The Hispanic origin question changed in three ways. "First, the wording of the question changed from 'Is this person Spanish/Hispanic/Latino?' in 2000 to 'Is this person of Hispanic, Latino, or Spanish origin?' in 2010. Second, in 2000, the question provided an instruction, 'Mark the 'No' box if not Spanish/Hispanic/Latino.' The 2010 Census question provided no specific instruction for non-Hispanic respondents. Third, in 2010, the 'Yes, another Hispanic, Latino, or Spanish origin’ category provided examples of six Hispanic origin groups (Argentinean, Colombian, Dominican, Nicaraguan, Salvadoran, Spaniard, and so on) and instructed respondents to 'print origin.' In 2000, no Hispanic origin examples were given” (Humes et al. 2011:2).
} 
data - data often used to study programs, policies, and American life, and worth understanding in and of themselves.

\section{RESULTS}

To What Extent Do Race/Hispanic Responses Change? Which Race/Hispanic Groups Are Most Affected by Response Change?

Overview of Race/Hispanic Response Change: To what extent, and in which race/ethnic groups, is response change happening? To address this, we first show a broad overview of the race and Hispanic response changes between 2000 and 2010. In Figure 1, we illustrate our data with a visual cross-tabulation. In the columns, we show 126 race and Hispanic origin response combinations for 2010 (six race groups, alone or in combination, repeated for each ethnicity group); in the rows, we show 64 race and Hispanic origin combinations for Census 2000 (62 of the possible response combinations have no cases in our data because of a case selection criterion). ${ }^{14}$ At the intersection of a row and column, the cell is darkened in accordance with the number of people with that response pattern (stable responses are shown on the diagonals of each quadrant and response changes on the off-diagonals).

We see three major patterns in the black and blue shaded boxes in Figure 1. First, response changes span the full variety of race and Hispanic origin groups; there are many shaded boxes throughout the figure and many of them denote a large number of people. Second, response changes are not only common among multiple-race respondents; many respondents are moving from one single-race response to another single-race response. Third, Hispanic origin

\footnotetext{
${ }^{14}$ Race response categories are not labeled in Figure 1 but are in the order used in the Census 2000 Summary File 1 (see U.S. Census Bureau 2007, pages 6-1 to 6-3).
} 
Figure 1. Overview of change and stability in race and Hispanic origin response between 2000 and 2010

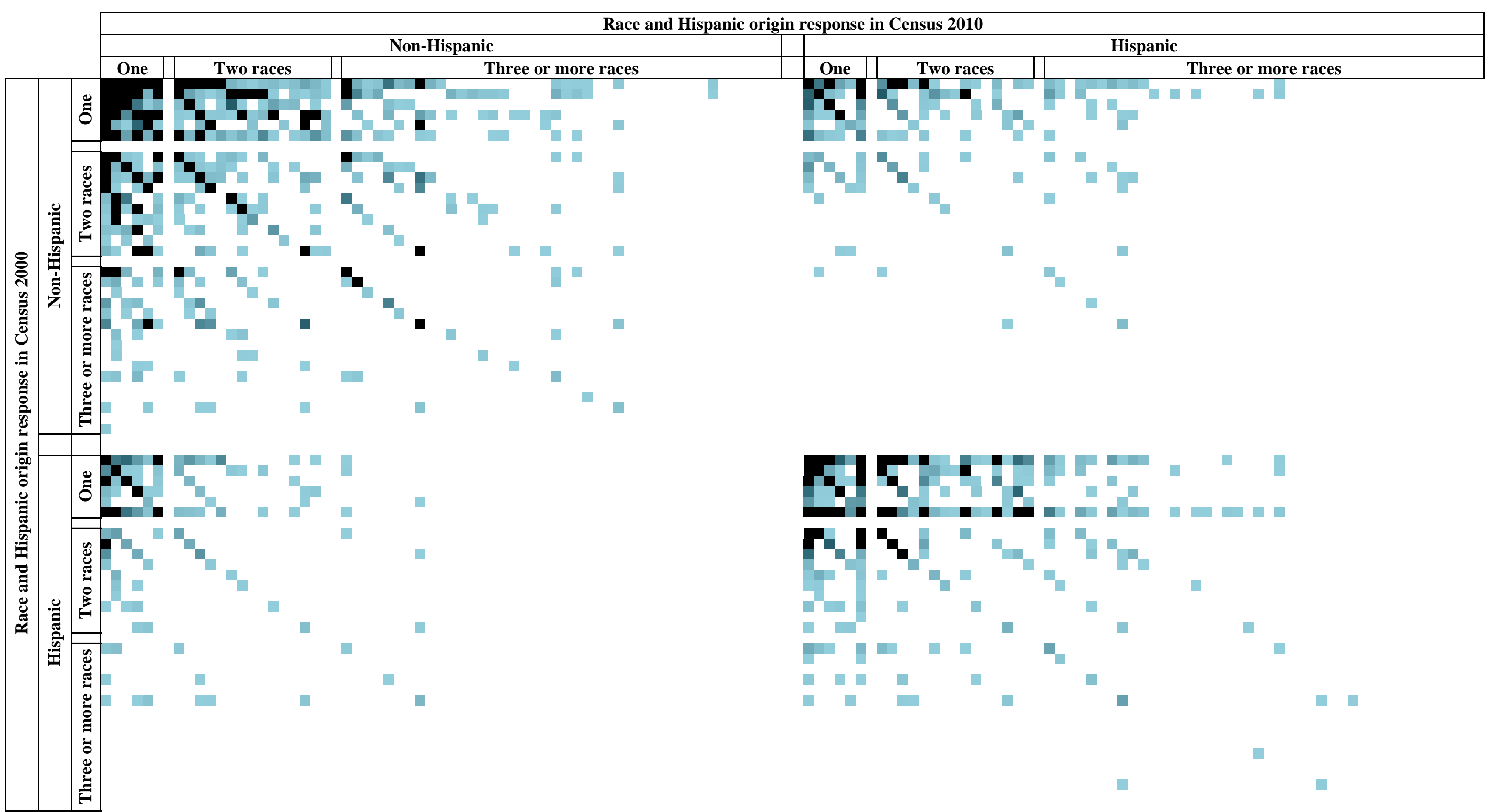

Notes: Only cases in the linked data are shown. People reported as Some Other Race in combination with another race in 2000 are not studied here because a processing error affected their responses. These 62 empty rows are not shown. The diagonals in each quadrant represent persons whose race response did not change, while the off-diagonals represent persons whose race response changed. Cells with 5,000 cases or more are black. Cells with 101 to 4,999 cases are shown in shades of blue (higher numbers are darker). Cells with 100 cases or less are white. 
responses change for many people; the top right quadrant and the bottom left quadrant are both well-populated with black and blue shaded boxes.

Moves into and out of race/Hispanic response groups: We next turn to a numerical summary of population flows into and out of race/Hispanic categories between the censuses of 2000 and 2010; see Table 2. The charts within Table 2 can be seen as Venn diagrams of overlapping rectangles. Each row includes all people with a particular race/Hispanic response combination, whether this was their response in 2000, 2010, or both. The light gray center section of each chart shows the proportion of people with the same response in both 2000 and in 2010. The red section on the left side represents the proportion with that response in 2000 but not 2010, and the blue section on the right represents the proportion with that response in 2010 but not $2000 .^{15}$

In general, Table 2 shows that single-race non-Hispanic whites, blacks, and Asians are largely stable groups - most of the same individuals are in each group in 2010 as were in the group in 2000. This is consistent with prior research results (Bentley et al. 2003; del Pinal and Schmidley 2005, Doyle and Kao 2007). For example, in 2000, there were about 125 million single-race non-Hispanic white people in our restricted data. Of these, about 123 million kept the same responses in 2010 .

The race/ethnic groups with smaller populations have a different story; the number of people who left or joined these groups is large relative to the number of people who stayed in the group - we use the term “churning” to describe population turnover between census years. For example, there was substantial churning in the Pacific Islander population between 2000 and 2010. About 153,000 people in our data were reported as single-race non-Hispanic Pacific

\footnotetext{
${ }^{15}$ See Appendix Table A for estimates of the effect of false matches on the numbers shown in Table 2.
} 
Table 2. Race response fluidity between Census 2000 and the 2010 Census, by Hispanic origin

\begin{tabular}{|c|c|c|c|c|c|c|}
\hline & $\begin{array}{r}(\mathrm{A}) \\
\text { Number in } \\
\underline{2000} \\
\end{array}$ & $\begin{array}{r}\text { (B) } \\
\text { Left } \\
\text { category }\end{array}$ & $\begin{array}{r}(\mathrm{C}) \\
\text { Stayed in } \\
\text { category }\end{array}$ & $\begin{array}{c}\text { (D) } \\
\text { Joined } \\
\text { category }\end{array}$ & $\begin{array}{r}(\mathrm{E}) \\
\text { Number in } \\
2010 \\
\end{array}$ & $\square \%$ Left $\square \%$ Stayed $\square \%$ Joined \\
\hline \multicolumn{7}{|l|}{ Non-Hispanic } \\
\hline white alone & $124,765,953$ & $2,000,840$ & $122,765,113$ & $1,391,841$ & $124,156,954$ & 97 \\
\hline black alone & $15,454,761$ & 573,247 & $14,881,514$ & 403,114 & $15,284,628$ & 94 \\
\hline AIAN alone & $1,045,627$ & 322,301 & 723,326 & 319,398 & $1,042,724$ & 53 \\
\hline Asian alone & $5,599,943$ & 264,709 & $5,335,234$ & 240,569 & $5,575,803$ & 91 \\
\hline NHPI alone & 152,640 & 52,441 & 100,199 & 54,726 & 154,925 & 48 \\
\hline SOR alone & 207,906 & 176,779 & 31,127 & 118,612 & 149,739 & 10 \\
\hline white \& black & 416,956 & 167,597 & 249,359 & 249,089 & 498,448 & 37 \\
\hline white \& AIAN & 575,680 & 441,157 & 134,523 & 515,927 & 650,450 & 12 \\
\hline white \& Asian & 499,837 & 219,765 & 280,072 & 311,370 & 591,442 & 35 \\
\hline white \& NHPI & 56,300 & 34,958 & 21,342 & 42,575 & 63,917 & 22 \\
\hline black \& AIAN & 79,222 & 62,789 & 16,433 & 82,488 & 98,921 & 10 \\
\hline black \& Asian & 50,482 & 26,179 & 24,303 & 34,010 & 58,313 & 29 \\
\hline black \& NHPI & 10,640 & 8,426 & 2,214 & 10,315 & 12,529 & 11 \\
\hline AIAN \& Asian & 21,344 & 18,868 & 2,476 & 13,492 & 15,968 & 7 \\
\hline AIAN \& NHPI & 2,393 & 1,948 & 445 & 2,221 & 2,666 & 10 \\
\hline Asian \& NHPI & 66,814 & 42,138 & 24,676 & 39,997 & 64,673 & 23 \\
\hline 3 or more races & 138,292 & 88,261 & 50,031 & 150,702 & 200,733 & 17 \\
\hline
\end{tabular}

Continued 
Table 2. continued. Race response fluidity between Census 2000 and the 2010 Census, by Hispanic origin

\begin{tabular}{|c|c|c|c|c|c|c|}
\hline & (A) & (B) & (C) & (D) & (E) & \\
\hline & $\begin{array}{r}\text { Number in } \\
\underline{2000} \\
\end{array}$ & $\begin{array}{r}\text { Left } \\
\text { category }\end{array}$ & $\begin{array}{l}\text { Stayed in } \\
\text { category }\end{array}$ & $\begin{array}{r}\text { Joined } \\
\text { category } \\
\end{array}$ & $\begin{array}{r}\text { Number in } \\
\underline{2010}\end{array}$ & $\square \%$ Left $\square \%$ Stayed $\square \%$ Joined \\
\hline \multicolumn{7}{|l|}{ Hispanic } \\
\hline white alone & $6,901,238$ & $1,990,063$ & $4,911,175$ & $3,229,894$ & $8,141,069$ & 48 \\
\hline black alone & 238,070 & 140,753 & 97,317 & 182,655 & 279,972 & 23 \\
\hline AIAN alone & 163,775 & 131,244 & 32,531 & 135,950 & 168,481 & +1 \\
\hline Asian alone & 50,981 & 34,939 & 16,042 & 35,982 & 52,024 & 18 \\
\hline NHPI alone & 12,245 & 10,014 & 2,231 & 8,953 & 11,184 & \\
\hline SOR alone & $5,011,234$ & 2,835,721 & $2,175,513$ & $1,438,711$ & $3,614,224$ & 34 \\
\hline white \& black & 36,990 & 28,401 & 8,589 & 42,387 & 50,976 & 11 \\
\hline white \& AIAN & 59,341 & 49,418 & 9,923 & 61,623 & 71,546 & 8 \\
\hline white \& Asian & 31,756 & 20,819 & 10,937 & 25,917 & 36,854 & 19 \\
\hline white \& NHPI & 5,701 & 4,437 & 1,264 & 4,559 & 5,823 & 12 \\
\hline black \& AIAN & 6,447 & 5,318 & 1,129 & 7,130 & 8,259 & \begin{tabular}{|l|l|}
8 & \\
\end{tabular} \\
\hline black \& Asian & 2,966 & 2,199 & 767 & 2,620 & 3,387 & 14 \\
\hline black \& NHPI & 823 & 734 & 89 & 849 & 938 & 5 \\
\hline AIAN \& Asian & 3,962 & 3,419 & 543 & 2,685 & 3,228 & \\
\hline AIAN \& NHPI & 641 & 586 & 55 & 718 & 773 & 4 \\
\hline Asian \& NHPI & 4,908 & 3,647 & 1,261 & 3,387 & 4,648 & 15 \\
\hline 3 or more races & 24,317 & 18,803 & 5,514 & 54,430 & 59,944 & 7 \\
\hline
\end{tabular}

AIAN = American Indian/Alaska Native; NHPI = Native Hawaiian and other Pacific Islander; SOR = Some Other Race.

Notes: Not shown above are those reporting multiple races including SOR in 2010 (135,431 non-Hispanic people and 474,836 Hispanic people). Case counts include only people in the linked data. Percentages are calculated as follows: $\%$ left $=B /(B+C+D)$; $\%$ stayed $=C /(B+C+D) ; \%$ joined $=D /(B+C+D)$. The percent who stayed in the category is shown for reference. It represents the percent of people who reported a race and Hispanic origin combination in both 2000 and 2010, of the people who reported that combination in either 2000 or 2010. 
Islander in 2000. Of these, about 52,000 gave a different response in 2010 (i.e., left) and another 55,000 joined the group. The size of the resulting 2010 population is quite similar to the 2000 population such that the high rate of turnover would be masked in cross-sectional data. The multiple-race groups shown in Table 2 have very high levels of response churning. The most consistent multiple-race response was non-Hispanic white-black; 37 percent of people in this group in either 2000 or 2010 reported it in both 2000 and 2010.

Three case studies of response churning: We next show three case studies of race/Hispanic origin groups with intertwined histories. These case studies focus on response stability and changes among people who reported some combination of (a) Hispanic, Some Other Race, and/or white (Table 3), (b) non-Hispanic black, non-Hispanic American Indian, and/or non-Hispanic white (Table 4), and (c) non-Hispanic Asian, non-Hispanic Pacific Islander, and/or non-Hispanic white (Table 5).

People who reported some combination of Hispanic, white, and/or Some Other Race in 2000 and/or 2010 comprise our first case study, shown in Table 3. In several places in this table, we see offsetting flows between responses. For example, a similar number of people changed their response from non-Hispanic Some Other Race to non-Hispanic white $(50,005)$ as changed from non-Hispanic white to non-Hispanic Some Other Race $(39,285)$. There are two situations in Table 3 that do not follow this pattern, both of which are consistent with the expected effects of design changes (c.f., Stokes et al. 2011). More people changed from non-Hispanic white to Hispanic white $(710,019)$ than from Hispanic white to non-Hispanic white $(417,855)$, perhaps because the word "origin" was added to the Hispanic origin question instructions. More people changed from Hispanic Some Other Race to Hispanic white $(2,380,183)$ than from Hispanic 
Table 3. Hispanic, white, and/or Some Other Race response stability and change

\begin{tabular}{|c|c|c|c|c|}
\hline \multirow[b]{2}{*}{$\begin{array}{l}\text { Race/Hispanic response in } \\
2000 \text { Census linked data }\end{array}$} & \multicolumn{4}{|c|}{ Race/Hispanic response in 2010 Census linked data } \\
\hline & H.W & H.SOR & NH.W & NH.SOR \\
\hline Hispanic white (H.W) & $4,911,175$ & $1,243,630$ & 417,855 & 6,396 \\
\hline Hispanic SOR (H.SOR) & $2,380,183$ & $2,175,513$ & 75,105 & 8,373 \\
\hline Non-Hispanic white (NH.W) & 710,019 & 74,222 & $122,765,113$ & 39,285 \\
\hline Non-Hispanic SOR (NH.SOR) & 4,112 & 3,368 & 50,005 & 31,127 \\
\hline
\end{tabular}

Notes: Case counts include only people in the linked data. SOR = Some Other Race, which is a response option on the census form. Other response changes are not shown. 
white to Hispanic Some Other Race $(1,243,630)$, perhaps related to the new text stating: "For this census, Hispanic origins are not races.”

In our second case study, we highlight response changes among non-Hispanic people who reported black, American Indian, and/or white in 2000 and/or 2010; see Table 4. These are the most long-standing U.S. populations, with many centuries of interracial unions and many people of mixed descent. We see substantial single-race-to-single-race response change between white and American Indian, again with complementary, countervailing flows. For example, 158,178 people changed from non-Hispanic American Indian to non-Hispanic white, while 173,415 people made the inverse response move.

There are also many people reporting one race in one census and reporting an additional race in the other census - this response change pattern is often more common than consistently reporting two races, with the multiple-race response more often in 2010. Gullickson and Morning (2011) and Guo et al. (2014) find evidence for relatively clear social rules about which race group part-blacks and part-American Indians should choose, encouraging part-blacks to report only black and part-American Indians to report their non-American Indian group(s). These patterns are also evident in the specific single-race responses given by those people moving between single- and multiple-race responses. However, these are patterns rather than rules; single-race black is not always chosen when reporting one race. For example, among whiteblacks in 2000, about 90,000 changed their response to single-race black in 2010 and about 36,000 changed their response to single-race white.

In our third case study (shown in Table 5), we highlight non-Hispanic Asian, Pacific Islander, and/or white responses. Part-Asians have been shown to be subject to a relatively flexible set of social rules about how they will racially classify, though most mixed-heritage 
Table 4. Non-Hispanic black, American Indian, and/or white response stability and change

\begin{tabular}{|c|c|c|c|c|c|c|}
\hline \multirow{2}{*}{$\begin{array}{l}\text { Race response } \\
\text { in } 2000 \text { Census } \\
\text { linked data }\end{array}$} & \multicolumn{6}{|c|}{ Race response in 2010 Census linked data } \\
\hline & B & AIAN & W & B \& AIAN & B \& W & AIAN \& W \\
\hline black (B) & $14,881,514$ & 22,793 & 112,882 & 71,382 & 130,788 & \\
\hline AIAN & 16,307 & 723,326 & 158,178 & 4,948 & & 99,910 \\
\hline white (W) & 102,464 & 173,415 & $122,765,113$ & & 67,879 & 404,209 \\
\hline B \& AIAN & 50,000 & 3,713 & & 16,433 & & \\
\hline B \& W & 90,086 & & 35,837 & & 249,359 & \\
\hline AIAN \& W & & 87,809 & 339,481 & & & 134,523 \\
\hline
\end{tabular}

Notes: Case counts include only people in the linked data. AIAN = American Indian and Alaska Native. All response categories shown are non-Hispanic. Other response changes are not shown. 
Table 5. Non-Hispanic Asian, Pacific Islander, and/or white response stability and change

\begin{tabular}{|c|c|c|c|c|c|c|}
\hline \multirow{2}{*}{$\begin{array}{l}\text { Race response } \\
\text { in } 2000 \text { Census } \\
\text { linked data }\end{array}$} & \multicolumn{6}{|c|}{ Race response in 2010 Census linked data } \\
\hline & A & NHPI & W & A \& NHPI & $A \& W$ & NHPI \& W \\
\hline Asian (A) & $5,335,234$ & 5,459 & 36,727 & 17,593 & 93,064 & \\
\hline NHPI & 4,598 & 100,199 & 6,115 & 10,270 & & 11,461 \\
\hline white (W) & 52,303 & 10,352 & $122,765,113$ & & 186,208 & 24,133 \\
\hline A \& NHPI & 20,425 & 10,031 & & 24,676 & & \\
\hline A \& W & 86,500 & & 102,888 & & 280,072 & \\
\hline NHPI \& W & & 11,815 & 15,416 & & & 21,342 \\
\hline
\end{tabular}

Notes: Case counts include only people in the linked data. NHPI = Native Hawaiian and other Pacific Islander. All response categories shown are non-Hispanic. Other response changes are not shown. 
Asians report multiple-races (Gullickson and Morning 2011; Liebler and DeRousse-Wu 2012).

Results in Table 5 are consistent with this prior work. Relative to results in Table 4, people who report a multiple-race in one year and a single race the other show less of a pronounced pattern in which single race was reported. We also see a tendency toward multiple-race responses in 2010 and some single-race-to-single-race response change, with a tendency away from white and toward Asian or Pacific Islander.

The three case studies reveal some general patterns. First, there are response changes throughout the tables. People who change their race and/or Hispanic response are making response moves in many different directions: between different single races, adding and dropping races, and changing whether they report Hispanic origins. Second, some single-race responses are favored over others when a person changes between a single-race and multiplerace response; except among non-Hispanic white-blacks, the largest of the groups is favored. Third, similar to findings from Table 2 (where the total number joining a group is broadly similar to the total number leaving), we observe similarly-sized flows between specific race/Hispanic origin groups. For example, the number of non-Hispanic Asians in 2000 who reported whiteAsian in 2010 (about 93,000 in Table 5) is similar in scale to the number of white-Asian people in 2000 who reported single-race Asian in 2010 (about 87,000). A researcher working with cross-sectional data might notice the 6,000-person net increase, but would not be alerted to the extent of race response churning.

Top 20 response changes: Next we investigate the top 20 most common race response changes in our data, as shown in Table 6 and Appendix Table B. This list of 20 groups rounds out our answer to the first research question which asked, in part: Which race/ethnic groups are most affected by response change? 
The two most common response changes, as shown in Table 6, are by people who change their race report but consistently identify as Hispanic: moving from Hispanic Some Other Race to Hispanic white, or the reverse - a result also shown above in Table 3. As mentioned, the imbalanced size of these response change flows may be partially explained by questionnaire design changes between the two censuses (see Stokes et al. 2011). These two most common changes make up 37 percent of race/Hispanic response changes in our data. ${ }^{16}$

There are at least three other notable patterns in the top 20 response moves. First, many of the common response moves involve adding or subtracting a race or Hispanic response; this is the case in 14 of the top 20 most common moves (ranks 3-7, 9, 11, 12, 14, and 16-20). Response changes from more than one race or Hispanic group to a single group (or the reverse) were anticipated by prior research on people who have salient connections to multiple groups (perhaps because their parents are from different groups) and relatively fluid identities (c.f., Rockquemore 1998; Root 1996).

Second, many common response changes involve movement between the majority group (non-Hispanic single-race white) and a minority group. Often this is a move between the majority group and a white-and-minority response (ranks 3-7, and 14 involve such a response change). Some of these response moves were anticipated by previous research showing variation in the racial identification of white-American Indian and white-Asian youth (Harris and Sim 2002; Doyle and Kao 2007), with a variety of factors predictive of response choices (c.f., Doyle and Kao 2007; Harris and Sim 2002; Liebler 2004, 2010; Xie and Goyette 1997).

\footnotetext{
${ }^{16}$ Two other common patterns (ranked $9^{\text {th }}$ and $11^{\text {th }}$ ) also show race response changes by people who are consistently identified as Hispanic.
} 
Third, a number of people change from one single-race group to another - most commonly from the majority group to/from non-Hispanic American Indian (ranks 8 and 10) or non-Hispanic black (ranks 13 and 15). In our data, more of these moves involve leaving the majority group, perhaps as a reflection of changes in the perceived costs and benefits of being a person of color. The fact that these response changers ever report non-Hispanic white raises the possibility that they are treating racial identity as "optional," in the sense that white ethnic identity has been found to be optional for some people (c.f., Waters 1990). Ethnicity can be "optional" or "symbolic" for white Americans because it is often without social costs (c.f., Gans 1979; Waters 1990) - but this is a special case of white privilege and not usually true for nonwhites whose physical appearance generates socially-enforced race labels imposed by others. Thus, these response change patterns are relatively unexpected.

\section{Characteristics of People Who Change Their Race/Hispanic Response}

Relative representation in the top 20: In our second research question, we ask about the characteristics of people whose race/Hispanic response changes. To answer this question, we use other information about each person - their age, sex, location, and enumeration mode - and display the relative presence of each characteristic among people in the 20 most common response change groups (right side of Table 6 and shown numerically in Appendix Table B). As illustrated in the top two rows in Table 6, response changers are more commonly children, people living in the West, and/or people in other response modes (such as non-response followup by an enumerator) in at least one census. Women are not overrepresented among response changers. We note that there are also many adults, people who live outside of the West, and/or who responded to the decennial censuses by mail among those whose race and/or Hispanic response changed across the decade. 
Table 6 shows interesting cross-group variation in the relative representation of children, people living in the West, and those using only the mail mode. ${ }^{17}$ People who were children in 2000 predominate among those changing from black to white-black, or vice versa (ranks 12 and 18), while adults made up the greatest proportion of those who reported combinations of white and American Indian (ranks 5, 6, 8, 10, 16, and 19). Those sometimes reporting Asian (ranks 17 and 20) or Hispanic SOR (ranks 1, 2, and 11) are more often found in the West, while those sometimes reporting black (ranks 12, 13, 15, and 18) are mostly in non-West regions. People who added or dropped the Hispanic origin designation (ranks 3 and 4) are less often in the West. Response changers who sometimes report white-Asian (ranks 7, 14, 17, and 20) more often use the mail mode than other people who change their responses. ${ }^{18}$ People who reported Hispanic SOR in 2010 but not 2000 (rank 2) or who made a single-race to single-race response change (ranks $8,10,13$, and 15) tended to respond to the decennial censuses using a response mode that uses an enumerator (i.e., not the mail mode). Previous research has found heightened response change when an enumerator is involved (c.f., Saperstein and Penner 2012).

\section{Does Race/Hispanic Response Churning Affect Social Science Researchers?}

Many researchers use race and Hispanic origin data from 2000 and 2010 to study changing characteristics of people, not considering that race and Hispanic origin responses can and do change. We next offer two types of information about the response changes evident in our data so that researchers can better understand how response changes might affect their own work. First, we show the extent of race and/or Hispanic response change by age, sex, and 12

\footnotetext{
${ }^{17}$ The red vertical bar in each column of Table 6 marks the average among response changers, as shown in the second row above the table.

${ }^{18}$ Some groups may be more likely than others to be visited by an enumerator. See note 6 .
} 
Table 6. Top 20 race/Hispanic response changes and the relative distribution within response change groups

\begin{tabular}{|c|c|c|c|c|c|c|c|}
\hline & Distribution & characteristics in the & ked data --> & $74 \%$ & $47 \%$ & $79 \%$ & $44 \%$ \\
\hline & Distribution & characteristics across & changers --> & $59 \%$ & $48 \%$ & $61 \%$ & $58 \%$ \\
\hline & & & & Relat & distribution of & sers within ch & e type \\
\hline Rank & 2000 response & 2010 response & \# Changing & Children : Adults & Women : Men & West : Else & Mail mode : Else \\
\hline 1 & Hispanic SOR & Hispanic white & $2,380,183$ & & & & \\
\hline 2 & Hispanic white & Hispanic SOR & $1,243,630$ & & & & \\
\hline 3 & white & Hispanic white & 710,019 & & & & \\
\hline 4 & Hispanic white & white & 417,855 & & & & \\
\hline 5 & white & white \& AIAN & 404,209 & & & & \\
\hline 6 & white \& AIAN & white & 339,481 & & & & \\
\hline 7 & white & white \& Asian & 186,208 & & & & \\
\hline 8 & white & AIAN & 173,415 & & & & \\
\hline 9 & Hispanic white & Hisp. white \& SOR & 163,826 & & & & \\
\hline 10 & AIAN & white & 158,178 & & & & \\
\hline 11 & Hispanic SOR & Hisp. white \& SOR & 132,032 & & & & \\
\hline 12 & black & white \& black & 130,788 & & & & \\
\hline 13 & black & white & 112,882 & & & & \\
\hline 14 & white \& Asian & white & 102,888 & & & & \\
\hline 15 & white & black & 102,464 & & & & \\
\hline 16 & AIAN & white \& AIAN & 99,910 & & & & \\
\hline 17 & Asian & white \& Asian & 93,064 & & & & \\
\hline 18 & white \& black & black & 90,086 & & & & \\
\hline 19 & white \& AIAN & AIAN & 87,809 & & & & \\
\hline 20 & white \& Asian & Asian & 86,500 & & & & \\
\hline All ot & er race/Hispanic & ponse changers & $2,567,491$ & & & & \\
\hline
\end{tabular}

Notes: Case counts include only people in the linked data. See Appendix B for case counts underlying the gray bars. SOR = Some Other Race; AIAN = American Indian/Alaska Native; children = age 0-17 in 2000; West = lived in the west region in 2000; mail mode = responded to the census through the mail in both years. Responses are non-Hispanic unless noted. 
race/ethnic groupings. For general reference, we use these percentages to calculate the extent of response change we would expect to have seen if all Census 2000 people had been included in our linked data. Second, we show the extent of response change remaining when race/ethnic categories are aggregated in common ways.

Extent of response change, by age and sex: In Table 7 we display the rates of race and/or Hispanic response change among people in our linked data, by age group, sex, and within 12 relatively large race/ethnic categories $(4$ ages $\mathrm{x} 2$ sexes $\mathrm{x} 12$ race/ethnic categories $=96$ subgroups; all variables are as of 2000). Each bar in Table 7 shows the percent of people within one of the 96 subpopulations who either: (a) had the same race and Hispanic origin response in 2010 as in 2000, (b) had a different race response, (c) had a different Hispanic response, or (d) had different race and Hispanic responses. The numbers underlying Table 7 are in Appendix Table C.

The rate of response change among single-race non-Hispanic whites, blacks, and Asians is low across all age and sex groups. In several other groups in Table 7, we see higher levels of response change but fairly little variation by age or by sex; this is true for non-Hispanic American Indians, Pacific Islanders, white-American Indians, other non-Hispanics, and Hispanics who report Some Other Race. For these groups, plausible explanations of race/Hispanic response change should not rest heavily on age or gender dynamics. Other groups in Table 7 show a more clear age and/or sex gradient in the percent whose race response changes over the decade. Among white-blacks and white-Asians, young people and women/girls are less apt to change responses. These groups are among the fastest-growing due to new interracial unions; perhaps the younger generation is more comfortable with a multiracial identity and does not feel forced to choose one race (see Korgen 1998). In contrast, young Hispanic whites are less 
Table 7. Race/Hispanic response change among people in the linked data, by sex, age, and race/ethnicity response in 2000



Notes: Charts include only people in the linked data. See Appendix Table C for underlying numbers. AIAN = American Indian/Alaska Native. 
stable in their race/Hispanic responses than are older Hispanic whites (with no clear sex difference); perhaps the reasons for choosing a white response are more embedded in the minds of older Hispanics (see Dowling 2014).

Our study so far has focused on the 162 million people in the linked data who fit our case selection criteria, but they are not a representative sample of any population. To get a sense of the extent of race and/or Hispanic response change we would expect to see if all Census 2000 persons were in our data, we have applied the proportions ${ }^{19}$ (shown in Appendix Table C) to all people in Census $2000 .^{20}$ For example, if there were 10,000 single-race non-Hispanic American Indian 10 year old boys enumerated in 2000, in 2010 we would expect 6,930 of them to report single-race non-Hispanic American Indian, 2,680 to give a different non-Hispanic race response, 200 to report Hispanic single-race American Indian, and 190 to report Hispanic and a different race. Applying these calculations to all people in Census 2000, we expect that 91.7 percent of the Census 2000 population (258,147,414 people) would have reported the same race and Hispanic origin in 2010, 7.0 percent would have changed their race response by $2010(19,658,164), 1.0$ percent would have changed only their Hispanic origin response by 2010 (2,683,977), and 0.3 percent would have changed both responses (932,351). Close to 6 percent (6.1 percent) of people in our sample had a different race and/or Hispanic origin response in 2010 than in 2000, but the expected rate is higher - 8.3 percent - when all Census 2000 people are included. This discrepancy is because those who are not in the linked data are disproportionately from groups with relatively high levels of response change.

\footnotetext{
${ }^{19}$ These expected values rest on the untested assumption that people who were not in the linked data are similar to those in the linked data (within race/Hispanic, sex, and age group) in terms of their tendency to change responses.

${ }^{20}$ There are no people in our linked data who have a race response of multiracial Some Other Race (because of a sample selection criterion; see note 11). To calculate the expected response change for people in this group, we applied the overall average rate of response change within the person's age, sex, and Hispanic origin group.
} 
Extent of response change when categories are combined for analysis: The race and Hispanic response churning shown in the linked data and estimated for the Census 2000 population has implications for analyses. To what extent is it possible to reduce cross-category response change by aggregating categories? Turning back to the linked data, we use Table 8 to illustrate the extent of response churning across a number of common aggregations of race/Hispanic groups (associated numbers are in Appendix Table D). Note that some aggregations (those that include "Hispanic or not") disregard changes into and out of the Hispanic origin designation. The last Hispanic origin aggregation ("Hispanic of any race”) disregards race response changes among Hispanics.

Because most people who ever report white report it consistently, the "white" group is not substantially affected by race category instability, whether or not the group is defined as including white Hispanics and/or multiple-race part-whites. Various aggregations of black respondents - and to a lesser extent Asian respondents - also show little difference in terms of the (non-) effect of race/Hispanic response change.

The four different strategies for coding Hispanics (by race or disregarding race responses) give different levels of response stability. A coding strategy that divided Hispanics into groups based on their single-race response (e.g., white versus Some Other Race) in 2000 would encounter substantial response change. Because people are relatively unlikely to add or drop their Hispanic designation but Hispanics show fluidity in their race responses, a researcher coding all Hispanic respondents into a single group (ignoring their race response) would be including most of the same individuals in 2000 as in 2010.

There is no such simple solution for categorizing American Indians, Pacific Islanders, or multiple-race people. About 53 percent of the single-race non-Hispanic American Indians in 
Table 8. Response change within common race/Hispanic aggregations

Focus on whites

white alone, non-Hispanic

white alone or in combination, non-Hispanic

white alone, Hispanic or not

white alone or in combination, Hispanic or not

$\square \%$ Left $\quad \square \%$ Stayed $\quad$ \%\% Joined

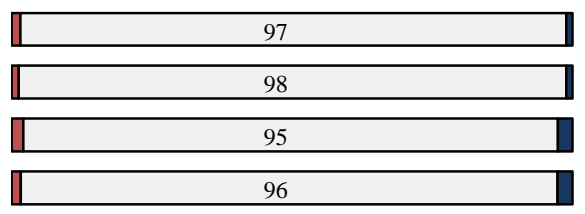

Focus on blacks

black alone, non-Hispanic

black alone or in combination, non-Hispanic

black alone, Hispanic or not

black alone or in combination, Hispanic or not

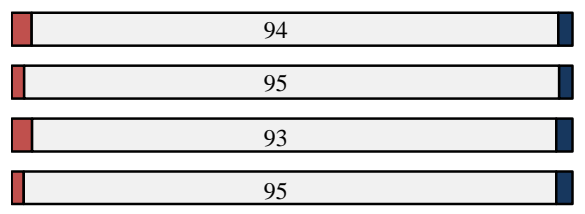

Focus on Asians

Asian alone, non-Hispanic

Asian alone or in combination, non-Hispanic

Asian alone, Hispanic or not

Asian alone or in combination, Hispanic or not

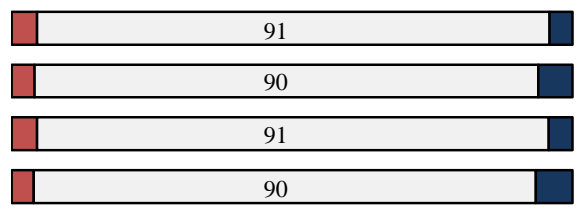

Focus on Hispanics

Hispanic white alone

Hispanic SOR alone

Hispanic white alone or SOR alone or white-SOR

Hispanic of any race(s)

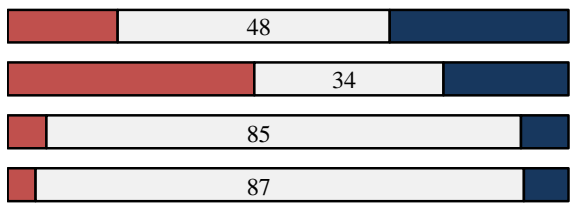

Focus on American Indian/Alaska Natives

AIAN alone, non-Hispanic

AIAN alone or in combination, non-Hispanic

AIAN alone, Hispanic or not

AIAN alone or in combination, Hispanic or not

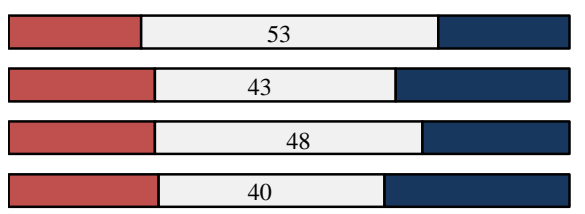

Focus on Native Hawaiians and other Pacific Islanders

NHPI alone, non-Hispanic

NHPI alone or in combination, non-Hispanic

NHPI alone, Hispanic or not

NHPI alone or in combination, Hispanic or not

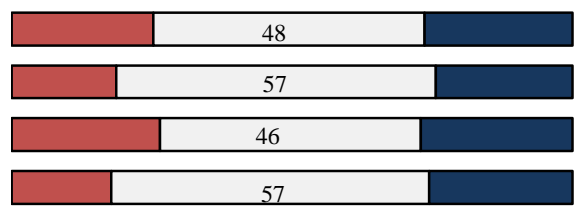

\section{Focus on multiracials}

Two or More Races, Hispanic or not

Notes: Only people in the linked data are shown; see Appendix Table D for case counts. Percentages are calculated as in Table 2. The percent who stayed in the category is shown for reference. AIAN = American Indian/Alaska Native; NHPI = Native Hawaiian and other Pacific Islander; SOR = Some Other Race. 
2000 reported the same race/Hispanic origin in 2010. Making the coding scheme very inclusive (American Indian alone or in combination, whether Hispanic or not) does not reduce response change (in fact, it does the opposite). In other words, when not reporting American Indian, new and former American Indians are otherwise identifying as entirely non-American Indian. The Pacific Islander populations differ from American Indians in their response patterns. Broadly aggregating Pacific Islanders (i.e., regardless of multiple-race responses or Hispanic identity) improves overlap between the 2000 and 2010 populations. Compared to American Indian response changers, Pacific Islander response changers are less often dropping the race group completely - more often they are keeping the Pacific Islander designation and adding or dropping other race responses.

\section{DISCUSSION AND CONCLUSION}

In this research, we have addressed core questions about race and Hispanic origin response change in the contemporary United States: To what extent do individuals' race and/or Hispanic origin responses change? Is change more common to/from some race/ethnic groups than others? Does the propensity to change responses vary by characteristics of the individual? To what extent do these changes affect researchers? We investigated these person-level changes in race and/or Hispanic origin responses using remarkable data: information about 162 million people whose responses in Census 2000 were linked to their responses in the 2010 Census. Our data allowed us to expand on prior research by including all federally-defined race and Hispanic origin groups, throughout the nation and of all ages. We are not the first to notice that people's race and Hispanic origin responses change, but we are the first to provide information about these changes on such a large and inclusive scale. 
To what extent do individuals' race and/or Hispanic origin responses change? We find that about 6 percent of people in our data had a different race and/or Hispanic origin response in 2010 than in 2000. Applying the rates in our data to all people in the United States in 2000, we estimate that 8.3 percent of all U.S. people would have changed their race and/or Hispanic origin response by 2010 if all had been included in the linked data.

People who change their race and/or Hispanic origin responses are doing so in a wide variety of ways, in patterns anticipated by previous research. People's responses change from multiple races to a single race, from a single race to multiple races, and from one single race to another. Some people add or drop a Hispanic response. There is a slight tendency toward multiple-race responses over the period and some evidence of effects of questionnaire design changes. Inflows to each race/Hispanic group are in many cases similar in size to the outflows from the same group such that cross-sectional data would show a small net change. Theoretical explanations for response change should take into account response churning - countervailing flows of response changes - as opposed to focusing on only one direction of response change.

Is change more common to/from some race/ethnic groups than others? The extent of response change varies by race/ethnic group, as found by prior researchers using smaller data sets. People in our data who reported single-race non-Hispanic white, black, or Asian usually did so in both 2000 and 2010. People are also usually consistent in their Hispanic/non-Hispanic response. On the other hand, there is extensive population churning among American Indians, Pacific Islanders, and multiple-race respondents in our data. Many people left each of these populations between 2000 and 2010, and about as many joined each group. A large number of Hispanics changed their race response (often consistent with questionnaire design changes). 
Does the propensity to change responses vary by characteristics of the individual?

Response changes happen throughout our society - among males and females, youth and adults, in all regions, and across response modes. At the same time, response changes are more common among people who were children and/or were living in the West in 2000, and/or who used another response mode besides mail in one or both years. We find variation in these patterns across the twenty most common response changes. For example, children are overrepresented among those changing responses between white-black and single-race black, while adults are overrepresented among people who change between white and/or American Indian responses.

To what extent do these changes affect researchers? Researchers who use race and/or Hispanic origin information about people in their studies will need to take into account the possibility of response changes. We detail response change rates in our data, by age, sex, and race/ethnic group, in the hopes that researchers will better understand the extent to which their research may be affected. With similar intentions, we report the response change rates evident in our linked data when the 126 possible combinations of race and Hispanic origin categories are aggregated in various common ways. This exercise reveals that aggregation decisions can notably increase or reduce response change rates in the Hispanic, American Indian, and Pacific Islander groups. Whites, blacks, and Asians show about the same levels of response change across age and sex groups and across different aggregation schemes.

Limitations: Like all research, our work has limitations. We have applied strict case selection rules and provide estimates of the false link rates (see Appendix Table A), but the possibility remains that a small proportion of response changes are due to faulty data links or cross-year differences in post-enumeration processing. It is also possible that some people purposely provide erroneous race or Hispanic origin information on the census or make mistakes 
when filling out their form, making their response changes meaningless. Most of the patterns of response change in the data (e.g., a person with a single race response in 2000 adding an additional race response in 2010) were anticipated by prior qualitative and quantitative research using other data sources, so we expect that most of the response changes reported in this paper are not due to these potential data issues.

We also are limited in the conclusions we can draw from these data. For example, with only two data points these data are not well suited to addressing questions of trends over time. We cannot know what the race and Hispanic responses mean to the individual (see note 2), nor have we investigated reasons for response change. It is likely that a wide variety of factors are involved in the complex processes reflected in our data, including personal identity formation, the social construction of race groups, interpersonal interactions bolstering or undermining identities, within-household dynamics affecting who responds and what they say, and political or social motivations for reporting one way rather than another. Our research does not tease apart these factors. Rather, we provide background information meant to be useful in further academic and public conversations about all of these fascinating topics.

Some implications: This research has implications for people collecting and working with data about race and ethnicity, as well as for those hoping to understand how race and ethnicity work in our society. In longitudinal data collection efforts, race and ethnicity could be measured at each wave. This would allow analysts to study the relationship between current race/ethnic responses and other factors and characteristics. It would also improve our understanding of whether and how people who change responses are having different experiences than those who do not change responses. When using cross-sectional data, analysts should keep in mind that the given race/ethnic response is effective for that point in time (and that measurement strategy), and 
may or may not have been the same in the past, in the future, or when assessed with different measures. This is the case for most other measured characteristics (e.g., education, location, and marital status). Given the results shown here, it should not be a surprise when population sizes and characteristics change for reasons related to changes in how people think of themselves and/or fill out a questionnaire.

At a conceptual level, our results highlight an oft-stated (but rarely incorporated) declaration - race and ethnicity are complex, multifaceted constructs. Taking this idea seriously puts the results of our research in a different light. If social science evidence is correct, people are constantly experiencing and negotiating their racial and ethnic identities in interactions with people and institutions, and in personal, local, national, and historical context. These racial and ethnic identities are not always able to be fully translated to a census questionnaire fixedcategory format. Perhaps it is not surprising that people change responses and instead it is surprising that so many are consistent in their race and Hispanic origin reports to the Census Bureau. 


\section{REFERENCES}

Alba, Richard and Tarquil Islam. 2009. “The Case of the Disappearing Mexican Americans: An Ethnic-Identity Mystery.” Population Research and Policy Review 28:109-121.

Barth, Fredrik (ed.). 1969. Ethnic Groups and Boundaries. Boston: Little, Brown, and Co.

Bentley, Michael, Tracy Mattingly, Christine Hough, and Claudette Bennett. 2003. "Census Quality Survey to Evaluate Responses to the Census 2000 Question on Race: An Introduction to the Data.” Census 2000 Evaluation B.3. Washington, DC: U.S. Census Bureau.

Bond, Brittany, J. David Brown, Adela Luque, and Amy O’Hara. 2013. “The Nature of the Bias When Studying Only Linkable Person Records: Evidence from the American Community Survey.” Proceedings of the 2013 Federal Committee on Statistical Methodology (FCSM) Research Conference. Washington, DC.

Compton, Elizabeth, Michael Bentley, Sharon Ennis and Sonya Rastogi. 2012. "2010 Census Race and Hispanic Origin Alternative Questionnaire Experiment.” DSSD 2010 CPEX Memorandum Series \#B-05-R, 2010 Census Planning Memoranda Series \#211, U.S. Washington, DC: U.S. Census Bureau.

Cornell, Stephen and Douglass Hartmann. 2007. Making Identities in a Changing World $\left(2^{\text {nd }}\right.$ Edition). Thousand Oaks, CA: Pine Forge Press.

Davis, F. James. 2001. Who is Black? One Nation's Definition, $10^{\text {th }}$ Anniversary Edition. University Park: Pennsylvania State University Press.

del Pinal, Jorge and Dianne Schmidley. 2005. "Matched Race and Hispanic Origin Responses from Census 2000 and Current Population Survey February to May 2000.” Population Division Working Paper No. 79. Washington, DC: U.S. Census Bureau

Dowling, Julie A. 2014. Mexican Americans and the Question of Race. Austin: University of Texas Press.

Doyle, Jamie M. and Grace Kao. 2007. “Are Racial Identities of Multiracials Stable? Changing Self-Identification among Single and Multiple Race Individuals.” Social Psychology Quarterly 70(4):405-423.

Duncan, Brian and Stephen J. Trejo. 2011. "Who Remains Mexican? Selective Ethnic Attrition and the Intergenerational Progress of Mexican Americans.” Pp. 285-320 in D. Leal and S. Trejo (Eds.), Latinos and the Economy. New York: Springer.

Dusch, Gianna and Fred Meier. 2012. “2010 Census Content Reinterview Survey Evaluation Report.” 2010 Census Program for Evaluations and Experiments. Washington, DC: U.S. Census Bureau.

Erickson, Erik. 1980. Identity and the Life Cycle. New York: Norton. 
Eschbach, Karl. 1993. "Changing Identification among American Indians and Alaska Natives.” Demography 30(4):635-652.

Eschbach, Karl. 1995. "The Enduring and Vanishing American Indian: American Indian Population Growth and Intermarriage in 1990.” Ethnic and Racial Studies 18:89-108.

Eschbach, Karl and Christina Gómez. 1998. "Choosing Hispanic Identity: Ethnic Identity Switching among Respondents to High School and Beyond.” Social Science Quarterly 79(1):74-90.

Eschbach, Karl, Khalil Supple, and C. Matthew Snipp. 1998. "Changes in Racial Identification and the Educational Attainment of American Indians, 1970-1990.” Demography 35(1):35-43.

Fallica, Heather, Sarah Heimel, Geoff Jackson, and Bei Zhang. 2012. “2010 Census Update Enumerate Operations Assessment: Update Enumerate Production, Update Enumerate Quality Control, Remote Update Enumerate, and Remote Alaska.” 2010 Census Program for Evaluations and Experiments. Washington, DC: U.S. Census Bureau.

Farley, Reynolds and John Haaga (eds.) 2005. The American People: Census 2000. New York: Russell Sage Foundation.

Fitzgerald, Kathleen J. 2007. Beyond White Ethnicity: Developing a Sociological Understanding of Native American Identity Reclamation. New York: Lexington Books.

Gans, Herbert. 1979. "Symbolic Ethnicity: The Future of Ethnic Groups and Cultures in America." Ethnic and Racial Studies 2(1):1-20.

Golash-Boza, Tanya and William Darity Jr. 2008. "Latino Racial Choices: The Effects of Skin Color and Discrimination on Latinos' and Latinas' Racial Self-identifications.” Ethnic and Racial Studies 31(5):899-934.

Grieco, Elizabeth M., and Rachel C. Cassidy. 2001. Overview of Race and Hispanic origin. Census 2000 Brief C2KBR/01-1. Washington, DC: U.S. Census Bureau.

Gullickson, Aaron and Ann Morning. 2011. "Choosing Race: Multiracial Ancestry and Identification.” Social Science Research 40:498-512.

Guo, Guang, Yilan Fu, Hedwig Lee, Tianji Cai, Kathleen Mullan Harris, and Yi Li. 2014. "Genetic Bio-Ancestry and Social Construction of Racial Classification in Social Surveys in the Contemporary United States.” Demography 51(1):141-172.

Haney López, Ian F. 1996. White by Law: The Legal Construction of Race. New York: New York University Press.

Harris, David. 1994. "The 1990 Census Count of American Indians: What Do the Numbers Really Mean?” Social Science Quarterly 75(2): 580-593. 
Harris, David and Jeremiah Joseph Sim. 2002. "Who is Multiracial? Assessing the Complexity of Lived Race.” American Sociological Review 67(4): 614-627.

Hemenway, David. 1997. "The Myth of Millions of Annual Self-Defense Gun Uses: A Case Study of Survey Overestimates of Rare Events." Chance 10(3):6-10.

Humes, Karen, Nicholas Jones, and Roberto Ramirez. 2011. Overview of Race and Hispanic Origin: 2010. 2010 Census Brief C2010BR-02. Washington, DC: U.S. Census Bureau.

Jones, Nicholas A. and Jungmiwha Bullock. “The Two or More Races Population: 2010.” Census 2010 Brief C2010BR-13. Washington, DC: U.S. Census Bureau.

Kana'iaupuni, Shawn and Carolyn A. Liebler. 2005. "Pondering Poi Dog: The Importance of Place to the Racial Identification of Mixed-race Native Hawaiians.” Ethnic and Racial Studies 28:687-721.

Khanna, Nikki. 2004. "The Role of Reflected Appraisals in Racial Identity: The Case of Multiracial Asians.” Social Psychology Quarterly 67(2):115-131.

Khanna, Nikki and Cathryn Johnson. 2010. "Passing as Black: Racial Identity Work among Biracial Americans.” Social Psychology Quarterly 73:380-397.

King-O’Riain, Rebecca Chiyoko. 2004. "Model Majority? The Struggle for Identity among Multiracial Japanese Americans." Pp. 177-192 in The Politics of Multiracialism: Challenging Racial Thinking, Heather M. Dalmage, ed. Albany: State University of New York Press.

Korgen, Kathleen. 1998. From Black to Biracial: Transforming Racial Identity among Biracial Americans.New York: Praeger.

Landale, Nancy S. and R.S. Oropesa. 2002. "White, Black, or Puerto Rican? Racial SelfIdentification among Mainland and Island Puerto Ricans.” Social Forces 81(1):231-254.

Lavrankas, Paul J., Matthew W. Courser and Lillian Diaz-Castillo. 2005. "What a Difference a Word Can Make: New Research on the Differences between Hispanic 'Origin’ and Hispanic 'Identity' and their Implications.” Paper presented at the 2005 AAPOR meetings. Miami Beach, Florida.

Layne, Mary, Deborah Wagner, and Cynthia Rothhaas. 2014. "Estimating Record Linkage False Match Rate for the Person Identification Validation System.” CARRA Working Paper Series (CARRA-02-14). Center for Administrative Records Research and Applications. Washington, DC: U.S. Census Bureau.

Liebler, Carolyn A. 2004. “Ties on the Fringes of Identity.” Social Science Research 33/4:702723.

Liebler, Carolyn A. 2010. "Homelands and Indigenous Identities in a Multiracial Era." Social Science Research 39:596-609. 
Liebler, Carolyn A. and Marie DeRousse-Wu. 2012. "Intergenerational Transmission of Race: Permeable Boundaries between 1970 and 2010.” Center for Economic Studies Working Paper 12-23. Washington, DC: U.S. Census Bureau.

Liebler, Carolyn A. and Shawn Kana'iaupuni. 2003/4. "Pacific Identities: Patterns in the Racial Identifications of Mixed-Race Pacific Islanders.” The Journal of Intergroup Relations 30(4):23-48.

Liebler, Carolyn A. and Timothy Ortyl. 2014. "More than a million new American Indians in 2000: Who are they?” Demography 51(3):1101-1130.

Logan, John. 2003. “How Race Counts for Hispanic Americans.” Lewis Mumford Center for Comparative Urban and Regional Research. The University at Albany, State University of New York.

Mehta, Neil K., Hedwig Lee, and Kelly R. Ylitalo. 2013. "Child Health in the United States: Recent Trends in Racial/Ethnic Disparities.” Social Science and Medicine 95:6-15.

Miville, Marie L., Madonna G. Constantine, Matthew F. Baysden, and Gloria So-Lloyd. 2005. "Chameleon Changes: An Exploration of Racial Identity Themes of Multiracial People." Journal of Counseling Psychology 52(4):507-516.

Mule, Thomas. 2012. "Census Coverage Measurement Estimation Report: Summary of Estimates of Coverage of Persons in the United States.” Washington, DC: U.S. Census Bureau.

Nagel, Joane. 1996. American Indian Ethnic Renewal: Red Power and the Resurgence of Identity and Culture. New York: Oxford University Press.

Office of Management and Budget. 1997. "Revisions to the Standards for the Classification of Federal Data on Race and Ethnicity." http://www.whitehouse.gov/omb/fedreg_1997standards

Passel, Jeffrey. 1976. "Provisional Evaluation of the 1970 Census Count of American Indians." Demography 13(3):397-409.

Passel, Jeffrey. 1997. "The Growing American Indian Population, 1960-1990: Beyond Demography.” Population Research and Policy Review 16(1-2):11-31.

Passel, Jeffrey and Patricia Berman. 1986. "Quality of 1980 Census data for American Indians.” Social Biology 33:163-182.

Perez, Anthony Daniel. 2008. "Who is Hispanic? Shades of Ethnicity among Latino/a Youth." Pp. 17-35 in Racism in Post-Race America: New Theories, New Directions. Charles Gallagher (ed). Chapel Hill, NC: Social Forces.

Robertson, Dwanna L. 2013. “A Necessary Evil: Framing an American Indian Legal Identity.” American Indian Culture and Research Journal 37(4):115-140. 
Rockquemore, Kerry A. 1998. "Between Black and White: Exploring the 'Biracial Experience.”" Race and Society 1(2):197-212.

Rodríguez, Clara E. 2000. Changing Race: Latinos, the Census, and the History of Ethnicity in the United States. New York: New York University Press.

Root, Maria P.P. (Ed.). 1996. The Multiracial Experience: Racial Borders as the New Frontier. Thousand Oaks, CA: Sage Publications.

Root, Maria. 1998. 'Experiences and Processes Affecting Racial Identity Development: Preliminary Results from the Biracial Sibling Project.” Cultural Diversity and Mental Health 4(3):237-47.

Saperstein, Aliya and Andrew Penner. 2012. "Racial Fluidity and Inequality in the United States.” American Journal of Sociology 118(3):676-727.

Saperstein, Aliya, Andrew M. Penner, and Ryan Light. 2013. "Racial Formation in Perspective: Connecting Individuals, Institutions, and Power Relations.” Annual Review of Sociology 39:359-378.

Singer, Phyllis and Sharon R. Ennis. 2003. "Census 2000 Content Reinterview Survey: Accuracy of Data for Selected Population and Housing Characteristics as Measured by Reinterview.” Census 2000 Evaluation B.5.Washington, DC: U.S. Census Bureau.

Snipp, C. Matthew. 2003. "Racial Measurement in the American Census: Past Practices and Implications for the Future." Annual Review of Sociology 29:563-588.

Spickard, Paul R. 2001. "Who is an Asian? Who is a Pacific Islander? Monoracialism, Multiracial People, and Asian American Communities.” Pp. 13-24 in The Sum of Our Parts: Mixed-Heritage Asian Americans, edited by Teresa Williams-León and Cynthia L. Nakashima. Philadelphia: Temple University Press.

Spickard, Paul R. and Rowena Fong. 1995. "Pacific Islander Americans and Multiethnicity: A Vision of America's Future?” Social Forces 73(4):1365-1383.

Stokes, Samantha, Courtney Reiser, Elizabeth Compton, Michael Bentley, and Cynthia Rothaas. 2011. "2010 Census Alternative Questionnaire Experiment (AQE): Census 2000 Form Replication Panel.” 2010 Census Program for Evaluations and Experiments. Washington, DC: U.S. Census Bureau.

Stokes-Brown, Atiya Kai. 2012. “America’s Shifting Color Line? Reexamining Determinants of Latino Racial Self-Identification.” Social Science Quarterly 93(2): 309-332.

Sturm, Circe. 2011. Becoming Indian: The Struggle over Cherokee Identity in the Twenty-first Century. Santa Fe, NM: School for Advanced Research Press.

Sweet, Elizabeth. 1994. "Who Fills Out the Census Questionnaire Study.” 1990 DSSD REX Memorandum Series \#PP-9. Washington, DC: U.S. Census Bureau. 
Tafoya, Sonya. 2004. "Shades of Belonging: Latinos and Racial Identity.” Washington, DC: Pew Hispanic Center.

Thornton, Russell. 1997. "Tribal Membership Requirements and the Demography of 'Old' and 'New’ Native Americans.” Population Research and Policy Review 16(1-2):33-42.

U.S. Census Bureau. 1993. “Content Reinterview Survey: Accuracy of Data for Selected Population and Housing Characteristics as Measured by Reinterview.” 1990 Census of Population and Housing Evaluation and Research Reports. Washington, DC: U.S. Census Bureau.

U.S. Census Bureau. 2003. Technical assessment of A.C.E Revision II. Washington, DC: U.S. Census Bureau.

U.S. Census Bureau. 2007. Summary File 1: 2000 Census of Population and Housing Technical Documentation.” Washington, DC: U.S. Census Bureau.

Wagner, Deborah, and Mary Layne. 2014. “The Person Identification Validation System (PVS): Applying the Center for Administrative Records Research and Applications' (CARRA) Record Linkage Software.” CARRA Working Paper Series (CARRA-01-14). Center for Administrative Records Research and Applications. Washington, DC: U.S. Census Bureau.

Walker, Shelley, Susanna Winder, Geoff Jackson, and Sarah Heimel. 2012. “2010 Census Nonresponse Followup Operations Assessment.” 2010 Census Program for Evaluations and Experiments. Washington, DC: U.S. Census Bureau.

Waters, Mary C. 1990. Ethnic Options: Choosing Identities in America. Berkeley: University of California Press.

Waters, Mary C. 1999. Black Identities: West Indian Immigrant Dreams and American Realities. Cambridge: Harvard University Press.

Wimmer, Andreas. 2013. Ethnic Boundary Making: Institutions, Power, Networks. New York: Oxford University Press.

Wright, Richard, Serin Houston, Mark Ellis, Steven Holloway, and Margaret Hudson. 2003. "Crossing Racial Lines: Geographies of Mixed-Race Partnering and Multiraciality in the United States.” Progress in Human Geography 27(4):457-474.

Xie, Yu and Kimberly Goyette. 1997. "The Racial Identification of Biracial Children with One Asian Parent: Evidence from the 1990 Census.” Social Forces 76(2): 547-570. 


\section{ACKNOWLEDGEMENTS}

We are grateful for helpful comments and suggestions from many people, including Mary Campbell, Jenifer Bratter, Steven Ruggles, Phyllis Moen, J. Trent Alexander, Caren Arbeit, Liying Luo, Susan Mason, Catherine Fitch, Joe Ritter, Mary Waters, Amy O’Hara, Eric Newburger, Nicholas Jones, Renuka Bhaskar, Sharon Lee, John Robert Warren, Gina Rumore, and Ramala Basu. The first author also received invaluable writing support from programs made possible by the Minnesota Population Center's NIH Center Grant (R24HD041023), University of Minnesota. 


\begin{tabular}{|c|c|c|c|c|c|c|c|c|}
\hline \multirow{4}{*}{$\begin{array}{r}\text { Non-Hispanic } \\
\text { white alone }\end{array}$} & \multirow[b]{2}{*}{$\begin{array}{c}\mathrm{N} \text { in } 2000 \text { in } \\
\text { data }\end{array}$} & \multirow{2}{*}{$\begin{array}{c}\% \text { of } \\
2000 \\
\text { pop in } \\
\text { data }\end{array}$} & \multirow{2}{*}{$\begin{array}{c}\text { Est. \# with } \\
\text { false match } \\
\text { (est } 1 \% \text { false } \\
\text { match rate) } \\
\end{array}$} & \multirow{2}{*}{$\begin{array}{l}\text { Of false } \\
\text { matches, } \\
\text { est. \# } \\
\text { matched to } \\
\text { this group }\end{array}$} & \multirow{2}{*}{$\begin{array}{c}\text { Est. \# } \\
\text { erroneously } \\
\text { coded as } \\
\text { left/joined } \\
\text { due to false } \\
\text { match }\end{array}$} & \multicolumn{3}{|c|}{$\begin{array}{c}\text { For reference: } \\
\text { Columns (B), (C), and (D) from Table } 2 \\
\end{array}$} \\
\hline & & & & & & $\begin{array}{r}\text { Left } \\
\text { category } \\
\end{array}$ & $\begin{array}{r}\text { Stayed in } \\
\text { category } \\
\end{array}$ & $\begin{array}{r}\text { Joined } \\
\text { category }\end{array}$ \\
\hline & (A) & (B) & $\begin{array}{c}(\mathrm{C})= \\
(\mathrm{A}) \mathrm{x} 1 \% \\
\end{array}$ & $\begin{array}{l}\text { (D) }= \\
\text { (B) } x(C)\end{array}$ & $\begin{array}{l}(E)= \\
(C)-(D)\end{array}$ & & & \\
\hline & $124,765,953$ & 0.772 & $1,247,660$ & 962,679 & 284,980 & $2,000,840$ & $122,765,113$ & 1,391,841 \\
\hline black alone & $15,454,761$ & 0.096 & 154,548 & 14,771 & 139,776 & 573,247 & $14,881,514$ & 403,114 \\
\hline AIAN alone & $1,045,627$ & 0.006 & 10,456 & 68 & 10,389 & 322,301 & 723,326 & 319,398 \\
\hline Asian alone & $5,599,943$ & 0.035 & 55,999 & 1,939 & 54,060 & 264,709 & $5,335,234$ & 240,569 \\
\hline NHPI alone & 152,640 & 0.001 & 1,526 & 1 & 1,525 & 52,441 & 100,199 & 54,726 \\
\hline SOR alone & 207,906 & 0.001 & 2,079 & 3 & 2,076 & 176,779 & 31,127 & 118,612 \\
\hline white \& black & 416,956 & 0.003 & 4,170 & 11 & 4,159 & 167,597 & 249,359 & 249,089 \\
\hline white \& AIAN & 575,680 & 0.004 & 5,757 & 20 & 5,736 & 441,157 & 134,523 & 515,927 \\
\hline white \& Asian & 499,837 & 0.003 & 4,998 & 15 & 4,983 & 219,765 & 280,072 & 311,370 \\
\hline white \& NHPI & 56,300 & 0.000 & 563 & 0 & 563 & 34,958 & 21,342 & 42,575 \\
\hline black \& AIAN & 79,222 & 0.000 & 792 & 0 & 792 & 62,789 & 16,433 & 82,488 \\
\hline black \& Asian & 50,482 & 0.000 & 505 & 0 & 505 & 26,179 & 24,303 & 34,010 \\
\hline black \& NHPI & 10,640 & 0.000 & 106 & 0 & 106 & 8,426 & 2,214 & 10,315 \\
\hline AIAN \& Asian & 21,344 & 0.000 & 213 & 0 & 213 & 18,868 & 2,476 & 13,492 \\
\hline AIAN \& NHPI & 2,393 & 0.000 & 24 & 0 & 24 & 1,948 & 445 & 2,221 \\
\hline Asian \& NHPI & 66,814 & 0.000 & 668 & 0 & 668 & 42,138 & 24,676 & 39,997 \\
\hline 3 or more races & 138,292 & 0.001 & 1,383 & 1 & 1,382 & 88,261 & 50,031 & 150,702 \\
\hline \multicolumn{9}{|l|}{ Hispanic } \\
\hline white alone & $6,901,238$ & 0.043 & 69,012 & 2,945 & 66,067 & $1,990,063$ & $4,911,175$ & $3,229,894$ \\
\hline black alone & 238,070 & 0.001 & 2,381 & 4 & 2,377 & 140,753 & 97,317 & 182,655 \\
\hline AIAN alone & 163,775 & 0.001 & 1,638 & 2 & 1,636 & 131,244 & 32,531 & 135,950 \\
\hline Asian alone & 50,981 & 0.000 & 510 & 0 & 510 & 34,939 & 16,042 & 35,982 \\
\hline NHPI alone & 12,245 & 0.000 & 122 & 0 & 122 & 10,014 & 2,231 & 8,953 \\
\hline SOR alone & $5,011,234$ & 0.031 & 50,112 & 1,553 & 48,559 & $2,835,721$ & $2,175,513$ & $1,438,711$ \\
\hline white \& black & 36,990 & 0.000 & 370 & 0 & 370 & 28,401 & 8,589 & 42,387 \\
\hline white \& AIAN & 59,341 & 0.000 & 593 & 0 & 593 & 49,418 & 9,923 & 61,623 \\
\hline white \& Asian & 31,756 & 0.000 & 318 & 0 & 317 & 20,819 & 10,937 & 25,917 \\
\hline white \& NHPI & 5,701 & 0.000 & 57 & 0 & 57 & 4,437 & 1,264 & 4,559 \\
\hline black \& AIAN & 6,447 & 0.000 & 64 & 0 & 64 & 5,318 & 1,129 & 7,130 \\
\hline black \& Asian & 2,966 & 0.000 & 30 & 0 & 30 & 2,199 & 767 & 2,620 \\
\hline black \& NHPI & 823 & 0.000 & 8 & 0 & 8 & 734 & 89 & 849 \\
\hline AIAN \& Asian & 3,962 & 0.000 & 40 & 0 & 40 & 3,419 & 543 & 2,685 \\
\hline AIAN \& NHPI & 641 & 0.000 & 6 & 0 & 6 & 586 & 55 & 718 \\
\hline Asian \& NHPI & 4,908 & 0.000 & 49 & 0 & 49 & 3,647 & 1,261 & 3,387 \\
\hline 3 or more races & 24,317 & 0.000 & 243 & 0 & 243 & 18,803 & 5,514 & 54,430 \\
\hline
\end{tabular}

Total in 2000--> 161,700,185

Est. total cases with false match --> $\quad 1,617,002$

Note: AIAN = American Indian/Alaska Native; NHPI = Native Hawaiian and other Pacific Islander; SOR = Some Other Race. 
Appendix Table B. Top 20 race/Hispanic response changes and characteristics of people within response change groups

\begin{tabular}{|c|c|c|c|c|c|c|c|}
\hline \multirow{3}{*}{\multicolumn{3}{|c|}{ Total number in the linked data }} & Total N & Children & Women & In the West & Mail mode \\
\hline & & & $161,700,185$ & $41,541,446$ & $84,953,197$ & $34,105,404$ & $90,255,482$ \\
\hline & & & $9,782,918$ & $3,980,365$ & $5,086,352$ & $3,860,816$ & $4,116,311$ \\
\hline Rank & 2000 response & 2010 response & \# Changing & Children & Women & In the West & Mail mode \\
\hline 1 & Hispanic SOR & Hispanic white & $2,380,183$ & 837,978 & $1,244,185$ & $1,119,377$ & $1,140,998$ \\
\hline 2 & Hispanic white & Hispanic SOR & $1,243,630$ & 521,385 & 630,744 & 610,804 & 372,985 \\
\hline 3 & white & Hispanic white & 710,019 & 367,441 & 372,630 & 236,918 & 362,400 \\
\hline 4 & Hispanic white & white & 417,855 & 187,422 & 217,432 & 152,688 & 191,104 \\
\hline 5 & white & AIAN \& white & 404,209 & 129,190 & 207,714 & 109,315 & 135,908 \\
\hline 6 & AIAN \& white & white & 339,481 & 94,686 & 176,138 & 99,602 & 143,539 \\
\hline 7 & white & Asian \& white & 186,208 & 90,242 & 89,294 & 74,667 & 105,448 \\
\hline 8 & white & AIAN & 173,415 & 58,060 & 86,451 & 40,138 & 58,939 \\
\hline 9 & Hispanic white & Hisp. white \& SOR & 163,826 & 68,937 & 84,469 & 71,798 & 73,700 \\
\hline 10 & AIAN & white & 158,178 & 46,433 & 78,804 & 43,054 & 54,796 \\
\hline 11 & Hispanic SOR & Hisp. white \& SOR & 132,032 & 47,585 & 67,565 & 67,170 & 62,284 \\
\hline 12 & black & black \& white & 130,788 & 82,700 & 69,791 & 28,934 & 50,348 \\
\hline 13 & black & white & 112,882 & 32,745 & 57,727 & 15,859 & 29,514 \\
\hline 14 & Asian \& white & white & 102,888 & 45,575 & 49,308 & 39,922 & 49,722 \\
\hline 15 & white & black & 102,464 & 37,082 & 52,015 & 17,454 & 25,009 \\
\hline 16 & AIAN & AIAN \& white & 99,910 & 36,349 & 54,106 & 36,049 & 32,662 \\
\hline 17 & Asian & Asian \& white & 93,064 & 38,321 & 50,285 & 43,817 & 50,601 \\
\hline 18 & black \& white & black & 90,086 & 63,797 & 44,826 & 20,729 & 42,654 \\
\hline 19 & AIAN \& white & AIAN & 87,809 & 32,566 & 45,653 & 28,242 & 33,570 \\
\hline 20 & Asian \& white & Asian & 86,500 & 34,311 & 44,859 & 37,472 & 48,007 \\
\hline \multicolumn{3}{|c|}{ all other race/Hispanic response changers } & $2,567,491$ & $1,127,560$ & $1,362,356$ & 966,807 & $1,052,123$ \\
\hline
\end{tabular}

Notes: Case counts include only people in the linked data. SOR = Some Other Race; AIAN = American Indian/Alaska Native; children = age 0-17 in 2000; West $=$ lived in the west region in 2000; mail mode $=$ responded to the census through the mail in both years. Responses are non-Hispanic unless noted . 
Appendix Table C. Percent in linked data making each response change, by sex, age, and race/ethnicity response in 2000

\begin{tabular}{|c|c|c|c|c|c|c|c|c|c|c|c|c|c|c|}
\hline \multicolumn{4}{|c|}{ Ages $0-14$ in 2000} & \multicolumn{4}{|c|}{ Ages $15-29$ in 2000} & \multicolumn{4}{|c|}{ Ages 30-44 in 2000} & \multicolumn{3}{|c|}{ Ages 45 and older in 2000} \\
\hline$\%$ & $\% \Delta$ & $\% \Delta$ & $\% \Delta$ & $\%$ & $\% \Delta$ & $\% \Delta$ & $\% \Delta$ & $\%$ & $\% \Delta$ & $\% \Delta$ & $\% \Delta$ & $\%$ & $\% \Delta$ & $\% \Delta$ \\
\hline$\underline{\text { Same }}$ & $\underline{\text { Race }}$ & $\underline{\text { Hisp }}$ & Both & $\underline{\text { Same }}$ & $\underline{\text { Race }}$ & $\underline{\text { Hisp }}$ & $\underline{\text { Both }}$ & $\underline{\text { Same }}$ & $\underline{\text { Race }}$ & $\underline{\text { Hisp }}$ & Both & $\underline{\text { Same }}$ & $\underline{\text { Race }}$ & Both \\
\hline
\end{tabular}

MALES:

Non-Hispanic

white alone

black alone

$\begin{array}{lllllll}96.8 & 1.5 & 1.3 & 0.3 & 98.1 & 1.1 & 0.7\end{array}$

$\begin{array}{llll}94.8 & 4.0 & 0.7 & 0.4\end{array}$

$\begin{array}{llll}95.3 & 3.8 & 0.6 & 0.3\end{array}$

$\begin{array}{llll}98.7 & 0.9 & 0.4 & 0.1\end{array}$

$\begin{array}{llll}99.2 & 0.5 & 0.2 & 0.0\end{array}$

AIAN alone

$69.3 \quad 26.8 \quad 2.0$

$\begin{array}{llll}65.5 & 31.6 & 1.4 & 1.5\end{array}$

$\begin{array}{llll}96.9 & 2.7 & 0.3 & 0.1\end{array}$

$\begin{array}{llll}97.7 & 2.0 & 0.2 & 0.1\end{array}$

Asian alone

$\begin{array}{llll}93.1 & 6.2 & 0.3 & 0.3\end{array}$

$\begin{array}{llll}94.2 & 5.3 & 0.3 & 0.2\end{array}$

$\begin{array}{llll}69.0 & 28.9 & 1.0 & 1.1\end{array}$

$\begin{array}{llll}69.2 & 29.2 & 0.9 & 0.8\end{array}$

NHPI alone

$62.7 \quad 32.2 \quad 1.5$

$\begin{array}{lll}61.4 & 35.4 & 0.8\end{array}$

2.4

$\begin{array}{llll}96.0 & 3.6 & 0.2 & 0.1\end{array}$

$\begin{array}{llll}96.8 & 2.9 & 0.2 & 0.1\end{array}$

white \& black

$\begin{array}{llll}54.3 & 44.0 & 0.6 & 1.1\end{array}$

$\begin{array}{llll}69.4 & 28.2 & 0.8 & 1.6\end{array}$

$\begin{array}{llll}70.4 & 27.7 & 0.7 & 1.2\end{array}$

white \& AIAN

$\begin{array}{llll}25.3 & 72.6 & 0.6 & 1.4\end{array}$

$\begin{array}{lll}17.3 & 81.4 & 0.3\end{array}$

$\begin{array}{llll}38.6 & 60.0 & 0.4 & 1.0\end{array}$

$\begin{array}{llll}20.2 & 78.8 & 0.2 & 0.8\end{array}$

white \& Asian

$63.5 \quad 34.9 \quad 0.8$

0.9

$\begin{array}{llll}21.7 & 77.5 & 0.2 & 0.6\end{array}$

$\begin{array}{llll}23.1 & 76.4 & 0.1 & 0.4\end{array}$

all other non-Hisp.

$29.7 \quad 66.0 \quad 1$.

0.8

$\begin{array}{llll}54.6 & 44.2 & 0.5 & 0.8\end{array}$

$\begin{array}{llll}45.7 & 53.3 & 0.4 & 0.6\end{array}$

$\begin{array}{llll}30.7 & 68.1 & 0.4 & 0.7\end{array}$

Hispanic

\begin{tabular}{|c|c|c|c|c|c|c|c|c|c|c|c|c|c|c|c|c|}
\hline white alone & 63.6 & 27.6 & 8.2 & 0.6 & 64.8 & 27.6 & 7.1 & 0.5 & 72.5 & 22.6 & 4.6 & 0.3 & 82.1 & 13.7 & 4.0 & 0.2 \\
\hline SOR alone & 45.1 & 52.2 & 0.3 & 2.4 & 44.0 & 53.9 & 0.1 & 1.9 & 44.6 & 54.0 & 0.1 & 1.3 & 38.9 & 59.9 & 0.1 & 1.2 \\
\hline Il other Hispanic & 30.4 & 47.6 & 12.8 & 9.2 & 23.9 & 3.8 & 12.5 & 9.7 & 26.8 & 55.7 & 11.0 & 6.5 & 31.0 & 50.5 & 12.5 & 6.0 \\
\hline
\end{tabular}

Continued 
Appendix Table C, continued.

\begin{tabular}{cccc}
\multicolumn{4}{c}{ Ages 0-14 in 2000 } \\
\hline$\%$ & $\% \Delta$ & $\% \Delta$ & $\% \Delta$ \\
Same & Race & Hisp & Both
\end{tabular}

\begin{tabular}{cccc}
\multicolumn{4}{c}{ Ages 15-29 in 2000 } \\
\hline$\%$ & $\% \Delta$ & $\% \Delta$ & $\% \Delta$ \\
Same & $\underline{\text { Race }}$ & $\underline{\text { Hisp }}$ & Both
\end{tabular}

\begin{tabular}{cccc}
\multicolumn{4}{c}{ Ages 30-44 in 2000 } \\
\hline$\%$ & $\% \Delta$ & $\% \Delta$ & $\% \Delta$ \\
Same & $\underline{\text { Race }}$ & $\underline{\text { Hisp }}$ & Both
\end{tabular}

Ages 45 and older in 2000

\section{FEMALES:}

Non-Hispanic

white alone

black alone

$\begin{array}{llll}96.7 & 1.6 & 1.4 & 0.4\end{array}$

AIAN alone

$94.8 \quad 3.9$

0.8

0.4

$98.0 \quad 1.1 \quad 0.7$

0.2

$\begin{array}{llll}98.7 & 0.8 & 0.4 & 0.1\end{array}$

$\begin{array}{llll}99.3 & 0.5 & 0.2 & 0.0\end{array}$

Asian alone

$68.7 \quad 27.2 \quad 2.1$

$\begin{array}{llll}96.0 & 3.2 & 0.6 & 0.3\end{array}$

$\begin{array}{llll}97.0 & 2.5 & 0.3 & 0.1\end{array}$

$\begin{array}{llll}97.7 & 1.9 & 0.2 & 0.1\end{array}$

$\begin{array}{llll}92.9 & 6.4 & 0.4 & 0.4\end{array}$

$\begin{array}{lll}68.2 & 28.9 \quad 1.5\end{array}$

1.4

$\begin{array}{llll}71.7 & 26.3 & 1.1 & 0.9\end{array}$

$\begin{array}{llll}71.1 & 27.4 & 0.8 & 0.7\end{array}$

NHPI alone

$62.4 \quad 32.9 \quad 1.2$

$\begin{array}{llll}94.1 & 5.3 & 0.3 & 0.2\end{array}$

$\begin{array}{llll}96.1 & 3.4 & 0.3 & 0.1\end{array}$

$\begin{array}{llll}96.9 & 2.7 & 0.3 & 0.1\end{array}$

white \& black

$\begin{array}{lllll}65.2 & 32.8 & 0.8 & 1.1\end{array}$

$\begin{array}{llll}62.5 & 33.9 & 1.0 & 2.6\end{array}$

$\begin{array}{llll}68.7 & 28.8 & 0.8 & 1.7\end{array}$

$\begin{array}{llll}68.6 & 29.4 & 0.7 & 1.3\end{array}$

white \& AIAN

$\begin{array}{llll}25.0 & 72.8 & 0.7 & 1.5\end{array}$

$\begin{array}{llll}59.0 & 39.1 & 0.7 & 1.2\end{array}$

$\begin{array}{llll}42.2 & 56.2 & 0.5 & 1.1\end{array}$

$\begin{array}{llll}21.7 & 77.0 & 0.3 & 1.0\end{array}$

white \& Asian

$\begin{array}{llll}64.7 & 33.6 & 0.9 & 0.8\end{array}$

$\begin{array}{llll}21.3 & 77.1 & 0.4 & 1.1\end{array}$

$\begin{array}{llll}25.2 & 74.0 & 0.3 & 0.6\end{array}$

$\begin{array}{llll}25.7 & 73.7 & 0.2 & 0.4\end{array}$

all other non-Hisp.

$\begin{array}{llll}29.6 & 66.0 & 1.4 & 3.0\end{array}$

$\begin{array}{llll}59.8 & 38.6 & 0.7 & 0.8\end{array}$

$\begin{array}{llll}48.6 & 50.2 & 0.5 & 0.6\end{array}$

$\begin{array}{llll}32.4 & 66.5 & 0.5 & 0.7\end{array}$

$\begin{array}{llll}27.5 & 69.1 & 1.0 & 2.4\end{array}$

$\begin{array}{llll}27.7 & 69.6 & 0.9 & 1.8\end{array}$

$\begin{array}{llll}25.9 & 72.2 & 0.6 & 1.3\end{array}$

Hispanic

\begin{tabular}{|c|c|c|c|c|c|c|c|c|c|c|c|c|c|c|c|c|}
\hline white alone & 63.4 & 28.2 & 7.8 & 0.6 & 67.3 & 25.5 & 6.8 & 0.4 & 73.9 & 20.8 & 5.0 & 0.3 & 82.5 & 12.9 & 4.4 & 0.2 \\
\hline SOR alone & 45.6 & 51.8 & 0.2 & 2.3 & 43.3 & 54.7 & 0.1 & 1.9 & 43.6 & 54.6 & 0.1 & 1.7 & 37.1 & 61.4 & 0.1 & 1.4 \\
\hline Il other Hispanic & 30.6 & 48.1 & 12.6 & 8.7 & 28.7 & 49.9 & 12.9 & 8.5 & 29.8 & 50.6 & 12.9 & 6.8 & 31.5 & 48.0 & 14.1 & 6.4 \\
\hline
\end{tabular}

Notes: Percentages include only people in the linked data. $\%$ Same $=$ Race and Hispanic reports were the same in 2000 and $2010 . \% \Delta$ Race $=$ Race report differed between 2000 and 2010. \% $\Delta$ Hisp $=$ Hispanic report differed between 2000 and 2010. \% $\Delta$ Both $=$ Both race report and Hispanic report differed between 2000 and 2010. AIAN = American Indian/Alaska Native; NHPI = Native Hawaiian and other Pacific Islander; SOR = Some Other Race. 


\section{Appendix Table D. Response change within common race/Hispanic aggregations}

\begin{tabular}{|c|c|c|c|c|c|}
\hline & (A) & (B) & (C) & (D) & (E) \\
\hline & $\begin{array}{r}\text { Number in } \\
\underline{2000} \\
\end{array}$ & $\begin{array}{r}\text { Left } \\
\text { category }\end{array}$ & $\begin{array}{l}\text { Stayed in } \\
\text { category }\end{array}$ & $\begin{array}{r}\text { Joined } \\
\text { category }\end{array}$ & $\begin{array}{r}\text { Number in } \\
2010 \\
\end{array}$ \\
\hline \multicolumn{6}{|l|}{ Focus on whites } \\
\hline white alone, non-Hispanic & $124,765,953$ & $2,000,840$ & $122,765,113$ & $1,391,841$ & $124,156,954$ \\
\hline white alone or in comb., non-Hispanic & $126,447,824$ & $1,635,457$ & $124,812,367$ & $1,384,149$ & $126,196,516$ \\
\hline white alone, Hispanic or not & $131,667,191$ & $2,863,029$ & $128,804,162$ & $3,493,861$ & $132,298,023$ \\
\hline white alone or in comb., Hisp. or not & $133,506,014$ & $2,235,805$ & $131,270,209$ & $3,635,860$ & $134,906,069$ \\
\hline \multicolumn{6}{|l|}{ Focus on blacks } \\
\hline black alone, non-Hispanic & $15,454,761$ & 573,247 & $14,881,514$ & 403,114 & $15,284,628$ \\
\hline black alone or in comb., non-Hispanic & $16,086,372$ & 377,399 & $15,708,973$ & 385,664 & $16,094,637$ \\
\hline black alone, Hispanic or not & $15,692,831$ & 593,704 & $15,099,127$ & 465,473 & $15,564,600$ \\
\hline black alone or in comb., Hisp. or not & $16,384,542$ & 363,255 & $16,021,287$ & 486,112 & $16,507,399$ \\
\hline \multicolumn{6}{|l|}{ Focus on Asians } \\
\hline Asian alone, non-Hispanic & $5,599,943$ & 264,709 & $5,335,234$ & 240,569 & $5,575,803$ \\
\hline Asian alone or in comb., non-Hispanic & $6,320,851$ & 277,503 & $6,043,348$ & 412,371 & $6,455,719$ \\
\hline Asian alone, Hispanic or not & $5,650,924$ & 270,975 & $5,379,949$ & 247,878 & $5,627,827$ \\
\hline Asian alone or in comb., Hispanic or not & $6,429,714$ & 274,242 & $6,155,472$ & 447,484 & $6,602,956$ \\
\hline \multicolumn{6}{|l|}{ Focus on Hispanics } \\
\hline Hispanic white alone & $6,901,238$ & $1,990,063$ & $4,911,175$ & $3,229,894$ & $8,141,069$ \\
\hline Hispanic SOR alone & $5,011,234$ & $2,835,721$ & $2,175,513$ & $1,438,711$ & $3,614,224$ \\
\hline Hispanic white or SOR or white-SOR & $11,912,472$ & 906,113 & $11,006,359$ & $1,097,717$ & $12,104,076$ \\
\hline Hispanic of any race(s) & $12,589,061$ & 680,096 & $11,908,965$ & $1,085,049$ & $12,994,014$ \\
\hline \multicolumn{6}{|l|}{ Focus on American Indian/Alaska Natives } \\
\hline AIAN alone, non-Hispanic & $1,045,627$ & 322,301 & 723,326 & 319,398 & $1,042,724$ \\
\hline AIAN alone or in comb., non-Hispanic & $1,800,942$ & 680,804 & $1,120,138$ & 807,872 & $1,928,010$ \\
\hline AIAN alone, Hispanic or not & $1,209,402$ & 428,000 & 781,402 & 429,803 & $1,211,205$ \\
\hline AIAN alone or in comb., Hisp. or not & $2,050,652$ & 819,995 & $1,230,657$ & $1,009,166$ & $2,239,823$ \\
\hline \multicolumn{6}{|c|}{ Focus on Native Hawaiians and other Pacific Islanders } \\
\hline NHPI alone, non-Hispanic & 152,640 & 52,441 & 100,199 & 54,726 & 154,925 \\
\hline NHPI alone or in comb., non-Hispanic & 346,590 & 85,548 & 261,042 & 111,709 & 372,751 \\
\hline NHPI alone, Hispanic or not & 164,885 & 59,882 & 105,003 & 61,106 & 166,109 \\
\hline NHPI alone or in comb., Hisp. or not & 380,422 & 90,957 & 289,465 & 130,676 & 420,141 \\
\hline \multicolumn{6}{|l|}{ Focus on multiracials } \\
\hline Two or More Races, Hispanic or not & $2,095,812$ & $1,090,939$ & $1,004,873$ & $2,063,585$ & $3,068,458$ \\
\hline
\end{tabular}

Notes: Case counts include only people in the linked data. "in comb." = in combination with another race or races. AIAN = American Indian/Alaska Native; NHPI = Native Hawaiian and other Pacific Islander; SOR = Some Other Race. 